\title{
LOS DEPÓSITOS DE OFRENDAS TIWANAKOTAS DE LA ISLA PARITI, LAGO TITICACA, BOLIVIA
}

\author{
TIWANAKU DEPOSITS OF OFFERINGS ON THE ISLAND OF PARITI, \\ LAKE TITICACA, BOLIVIA
}

\author{
Antti Korpisaari ${ }^{1}$, Jédu Sagárnaga ${ }^{2}$, Juan Villanueva ${ }^{3}$ y Tania Patiño ${ }^{4}$
}

\begin{abstract}
Desde 1998, un equipo arqueológico finlandés-boliviano viene realizando excavaciones en el cantón Cascachi (Provincia Los Andes, Departamento de La Paz). En este artículo discutimos los resultados de nuestras investigaciones en la isla de Pariti, realizadas los años 2004-2006. Nos concentramos en la descripción y el análisis del material cultural recuperado en dos bolsones llenos de cerámica tiwanakota quebrada intencionalmente, datados en la segunda mitad del siglo X d.C. Estos bolsones -llamados rasgos 1 y 2 - contenían tiestos pertenecientes a por lo menos 435 vasijas, la mayoría de las cuales pudimos reconstruir en mayor o menor medida. La colección resultante incluye 56 kerus, 67 ch'alladores, 43 tazones, 82 escudillas, 26 botellones, 24 fuentes con pedestal, 7 wako retratos, 7 tinajas y 6 sahumadores, es decir, formas típicas tiwanakotas. Sin embargo, hay también una cantidad alta de vasijas de formas inéditas en la bibliografía arqueológica y/o poco conocidas, como las 45 denominadas vasijas "arriñonadas". La colección de Pariti forma parte de una de las muestras más importantes de cerámica tiwanakota tardía en los Andes Sur Centrales y ofrece muchos datos nuevos para el mejor entendimiento del fenómeno Tiwanaku.
\end{abstract}

Palabras claves: arqueología, Tiwanaku, cerámica votiva, Lago Titicaca, Andes Sur Centrales, Bolivia.

Since 1998, a team of Finnish and Bolivian archaeologists have been excavating in the Canton of Cascachi (Los Andes Province, Department of La Paz). In this article we discuss the results of our investigations on the Island of Pariti in 2004-2006. We concentrate on describing and analyzing the cultural material recovered in two deep pits filled with intentionally smashed Tiwanaku pottery, dating from the second half of the tenth century A.D. These pits -the so-called features 1 and 2-contained sherds belonging to at least 435 vessels, the majority of which we were able to reconstruct more or less completely. The resulting collection includes 56 kerus, 67 ch'alladores, 43 tazones, 82 escudillas, 26 bottles, 24 pedestal bowls, 7 portrait vessels, 7 tinajas, and 6 sahumadores, that is, typical Tiwanaku-period forms. However, there are also several vessels whose forms were little known or even virtually unknown prior to our discoveries, such as the 45 so-called kidney-shaped bowls. The Pariti collection is one of the most important assemblages of late Tiwanaku ceramics in the South Central Andes and offers new data to better understand the Tiwanaku phenomenon.

Key words: Archaeology, Tiwanaku, votive pottery, Lake Titicaca, South Central Andes, Bolivia.

Las crónicas coloniales señalan que el Lago Titicaca jugaba un rol religioso muy importante en el siglo XVI, ubicándose en Copacabana y las islas del Sol y de la Luna uno de los complejos de templos más importantes del Tawantinsuyu (Cobo 1990 [1653]:91-99; Ramos Gavilán 1988 [1621]). La arqueología sugiere que dicha porción del Titicaca, el lago Mayor, habría jugado un rol sacro también en tiempos anteriores. Investigaciones subacuáticas cerca de la isla del Sol revelaron ofrendas tiwanakotas (Ponce et al. 1992), y excavaciones recientes en las islas del Sol y de la Luna han documentado importantes sitios tiwanakotas cerca y/o debajo de los santuarios incas (Bauer y Stanish 2001; Stanish y Bauer 2004). Sin embargo, las investigaciones boliviano-finlandesas de los años 2004-2006 han brindado evidencias de que Tiwanaku tenía asimismo lugares de carácter fuertemente sacro en la porción meridional del Titicaca o lago Menor, específicamente en la isla de Pariti. En este artículo se describirán el contexto y el contenido de las ofrendas cerámicas de Pariti, y se discutirá respecto al carácter sacro de estos contextos y a las particularidades del ceremonial tiwanakota en el lago Menor.

1 Departamento de Culturas del Mundo, Universidad de Helsinki, Casilla 59, 00014 Universidad de Helsinki, Finlandia. antti.korpisaari@helsinki.fi

2 Scientia, Casilla 6520, La Paz, Bolivia. sagmar@megalink.com

3 Programa de Postgrado en Arqueología, Universidad de Tarapacá, Arica, Chile. juan710@ gmail.com

4 Proyecto Arqueológico “Chachapuma”, La Paz, Bolivia. tania.culturas2010@gmail.com 
La isla de Pariti se encuentra en la porción menor del Lago Titicaca (Figura 1). Su longitud es de aprox. $4 \mathrm{~km} \mathrm{y} \mathrm{su} \mathrm{ancho} \mathrm{mayor} \mathrm{mide} \mathrm{aprox.}$ $900 \mathrm{~m}$. El arqueólogo estadounidense Bennett fue el primer investigador que excavó en Pariti en 1934 (Bennett 1936). En ocho trincheras encontró material cultural asociado al período Formativo Temprano y/o Medio (ca. 1.500-200 a.C.), al período Tiwanaku (ca. 500-1.100 d.C.) y a la época Inca. El contexto más importante descubierto por Bennett fue una tumba tiwanakota que contenía 23 pequeños artefactos de oro. Gracias al informe publicado por Bennett (1936) y a un escrito de Posnansky (1957:III) sabemos que con anterioridad a las excavaciones de 1934 los entonces propietarios de la hacienda de Pariti habían encontrado oro y vasijas cerámicas en sus campos de cultivo. Lamentablemente estos artefactos, así como una parte de la colección de Bennett, han desaparecido.

Nuestro equipo finlandés-boliviano visitó Pariti por primera vez en 2002, y en 2003 supo que años antes unos comunarios habían encontrado

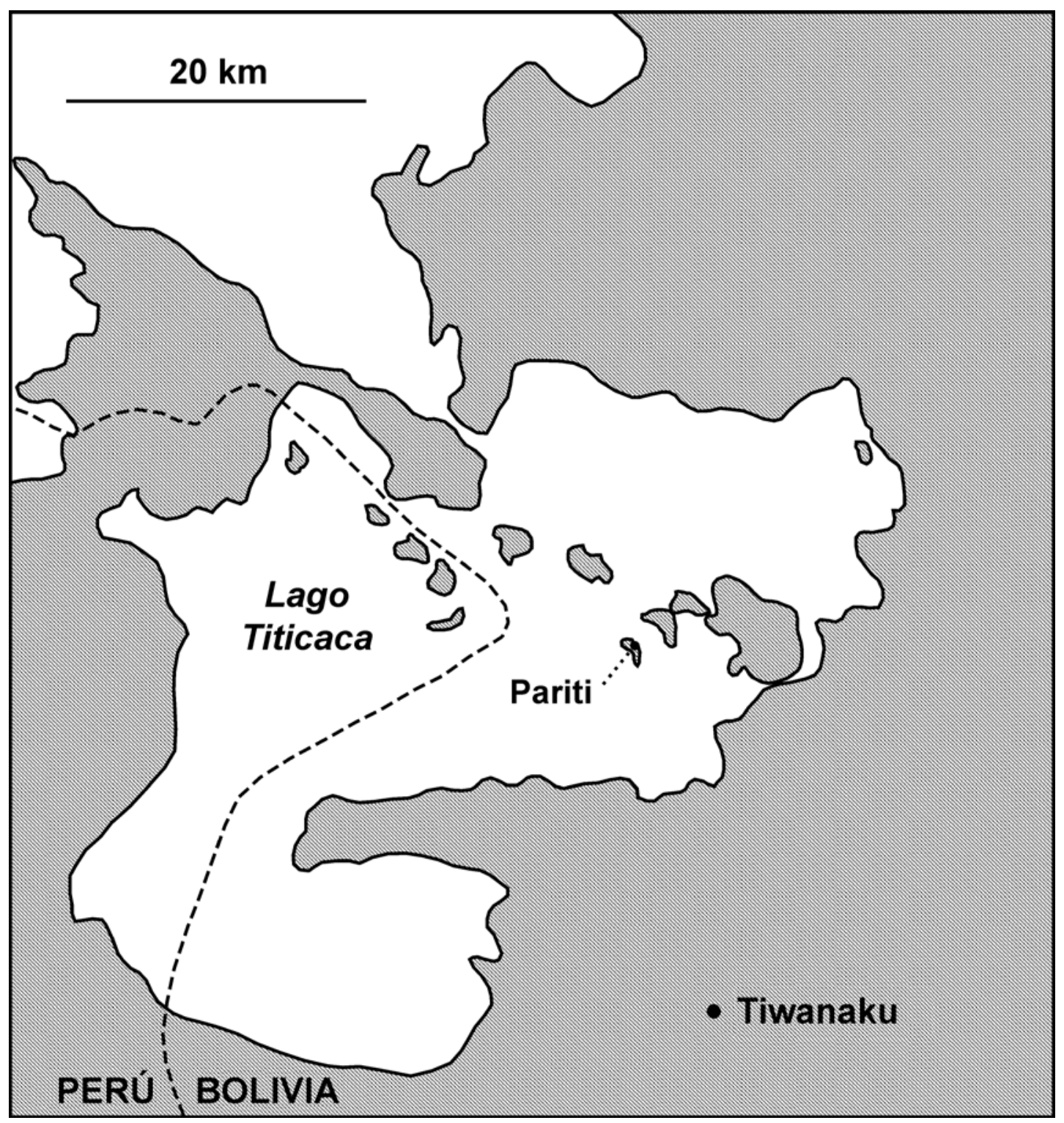

Figura 1. Mapa de la porción menor del Lago Titicaca y sus alrededores, mostrando la posición de la isla de Pariti (dibujo de A. Korpisaari).

Map of the smaller part of Lake Titicaca and surrounding areas showing the position of the island of Pariti (drawn by A. Korpisaari). 
un bolsón que contenía cerámica tiwanakota muy fina, en la cancha de fútbol de la comunidad de Pariti. Recuperamos parte de ese lote de piezas y su impresionante calidad nos motivó a hacer unas excavaciones en Pariti en agosto de 2004 (véase Korpisaari y Pärssinen 2005, 2011; Korpisaari y Sagárnaga 2007, 2009; Korpisaari et al. 2011). Nuestro segundo pozo de prueba se situó cerca a la esquina noroeste de la cancha (Figura 2). En este pozo, a unos $140 \mathrm{~cm}$ de profundidad, encontramos una concentración densa de cerámica. Se trataba de un bolsón con un diámetro de aproximadamente $70-80 \mathrm{~cm}$ y una profundidad de unos $170 \mathrm{~cm}$. El bolsón-denominado rasgo 1-contenía una cantidad inmensa de fragmentos de cerámica tiwanakota y unos 13,5 kg de hueso animal. Al parecer, la mayoría de la cerámica había sido quebrada intencionalmente en otro lugar, y los tiestos se echaron al pozo mezclados con restos de varios camélidos y otros animales.

Al excavar el rasgo 1 nos topamos con otro similar-denominado rasgo 2-que excavamos en abril del 2005 (Korpisaari y Pärssinen 2011; Korpisaari y Sagárnaga 2007; Sagárnaga y Korpisaari 2009). El rasgo 2 era un poco más pequeño que el rasgo 1: su diámetro era de unos $60 \mathrm{~cm}$ y su profundidad total llegaba a $170 \mathrm{~cm}$ (Figura 3).

Además de los rasgos mencionados, en tres temporadas de campo (2004-2006) hemos podido excavar un área de $32 \mathrm{~m}^{2}$ en el contorno de estos bolsones. Hemos encontrado restos de muros o cimientos bien preservados, construidos en por lo menos dos fases en base a piedras no labradas (Figura 4). Aunque falta ampliar el área de excavación, parece que los rasgos 1 y 2 se situaban próximos a una extensa construcción de muros de doble hilera, quizás un templo u otro tipo de edificio público. No poseemos información detallada sobre la disposición y la arquitectura de esta estructura, pues solamente hemos sacado a la luz dos secciones de muro/cimiento, ambas de ca. 4 metros de longitud, y la parte mejor preservada de ca. $70 \mathrm{~cm}$ de altura. Por la presencia de pocas evidencias de colapso de muros altos de piedra o de adobe, es posible que se tratara de un espacio abierto amurallado. Como fuese, la asociación temporal entre esta construcción y los dos bolsones es sugerida por la presencia de tiestos de kerus prosopomorfos - parecidos a ceramios de este tipo recuperados en los rasgos 1 y $2-$ en el relleno arcilloso situado entre ambas hileras del muro (Patiño y Villanueva 2006).
Del rasgo 1 tenemos cinco dataciones radiocarbónicas de diferentes profundidades. Del rasgo 2, otras tres (Tabla 1). La datación combinada (calibrada a dos sigmas con el programa OxCal v.3.10) del rasgo 1 es 890-1.000 cal. d.C., la del rasgo 2 es 990-1.150 cal. d.C. Dado que los tiestos de algunas vasijas se encontraban presentes en ambos rasgos, es probable que ambos bolsones se conformaran simultáneamente. Los rangos de dos sigmas de las dataciones combinadas en ambos bolsones se superponen en el período comprendido entre 990-1.000 años cal. d.C. Por consiguiente, parece ser que la formación de los rasgos 1 y 2 tuvo lugar aproximadamente el año 1.000 d.C. La combinación de los ocho fechados de ambos rasgos provee una fecha concordante (calibrada a dos sigmas): 980-1.025 cal. d.C.

\section{La Colección Cerámica de los Rasgos 1 y 2 de Pariti}

Dado que en los rasgos 1 y 2 encontramos tiestos pertenecientes a cientos de vasijas quebradas intencionalmente, pudimos reconstruir 435 de estas vasijas más o menos completamente. El rasgo 1 contenía los restos de al menos 311 vasijas, mientras que el rasgo 2, los restos de al menos 105 . Tiestos que pertenecían a otras 19 vasijas se encontraban divididos entre los dos rasgos, indicando que ambos bolsones probablemente se formaron al mismo tiempo como un par. La concepción dualista también se manifiesta en el gran porcentaje de vasijas de la colección de ambos rasgos que poseen pares más o menos exactos (véase Korpisaari y Pärssinen 2011; Sagárnaga 2009). Incluso algunas vasijas que no tenían par en su propio rasgo lo tenían en el otro, reforzando así la interpretación de la contemporaneidad de los dos bolsones.

La colección de los rasgos 1 y 2 de Pariti está constituida parcialmente por formas típicas, como kerus, ch'alladores, tazones, escudillas, botellones, fuentes con pedestal, wako retratos, tinajas y sahumadores (Tabla 2). El 73,1\% de las vasijas de la colección pertenecen a las nueve categorías susodichas, cuyas características más llamativas presentamos a continuación.

\section{Kerus}

De los 56 kerus, 28 (50\%) llevan decoración plástica de una forma u otra. Tres vasos llevan 


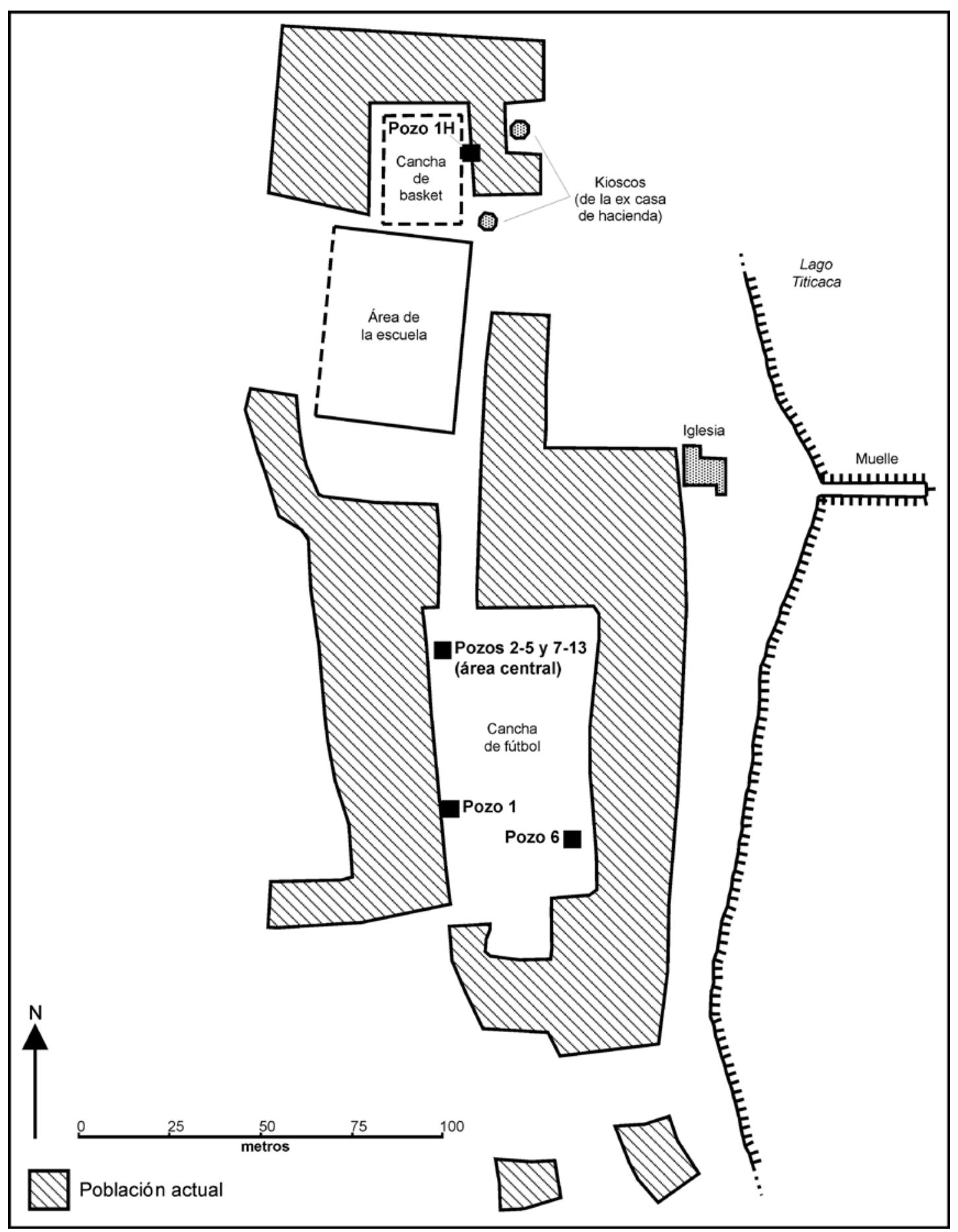

Figura 2. Plano general de la comunidad actual de Pariti y la ubicación de las unidades de excavación (2004-2006) (dibujo de A. Korpisaari en base a un mapa original de R. Väisänen y A. Korpisaari).

General plan of the present-day community of Pariti and the locations of the excavation areas (2004-2006) (redrawn by A. Korpisaari from an original by $\mathrm{R}$. Väisänen and $\mathrm{A}$. Korpisaari). 


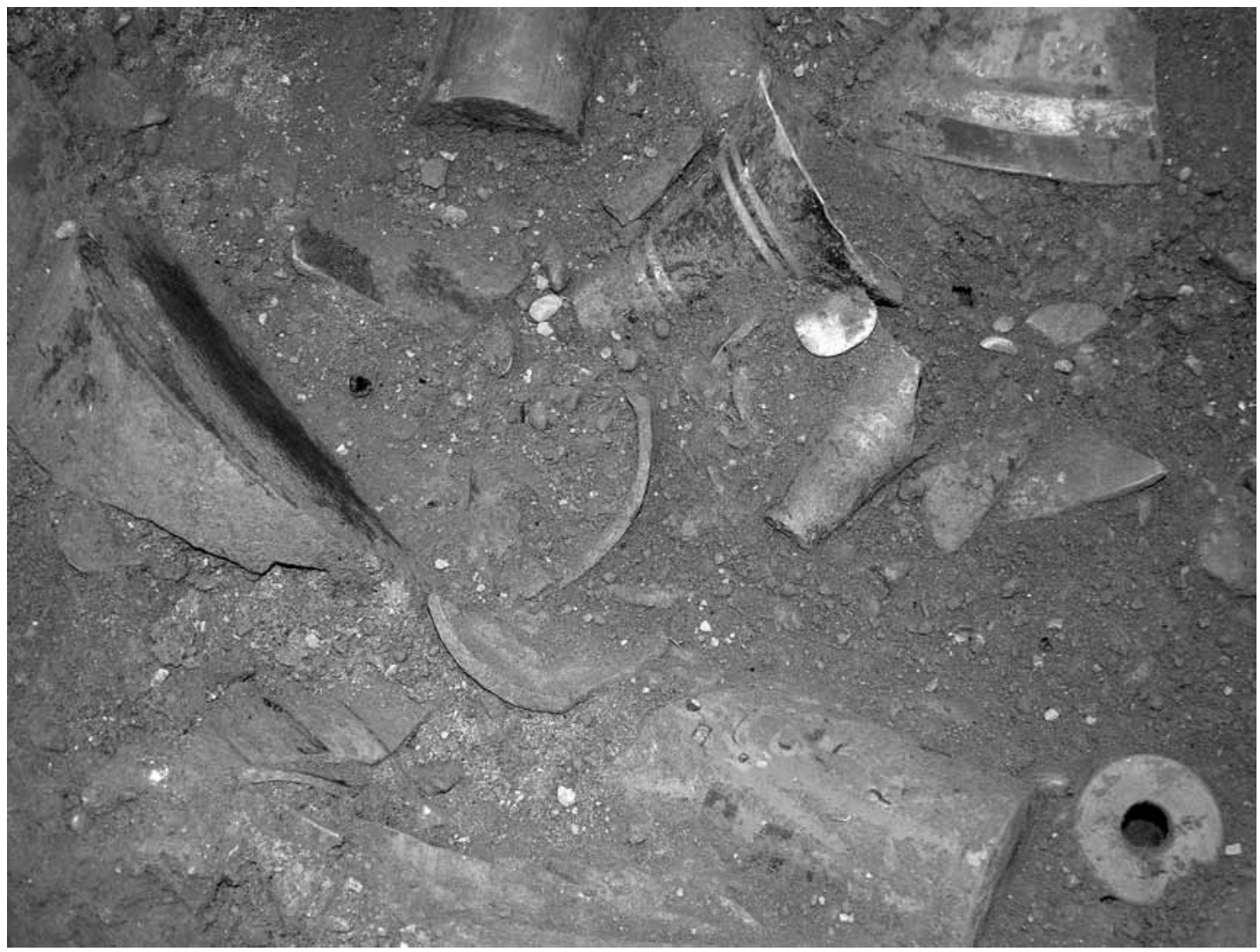

Figura 3. Cerámica in situ en el rasgo 2 de Pariti, a una profundidad de $205 \mathrm{~cm}$ (foto A. Korpisaari).

Pottery in situ in Pariti's feature 2, at a depth of $205 \mathrm{~cm}$ (photo A. Korpisaari).

la imagen parcialmente modelada del llamado "Dios de los Báculos" (Figura 5), mientras que $16(28,6 \%)$ son prosopomorfos, es decir, llevan una representación parcialmente modelada de la "Deidad Radiada" (véase Sagárnaga 2007). Además, cinco kerus llevan una cara modelada sin la característica "corona" o círculo de rayos de la "Deidad Radiada". Dos kerus son exornados por tres caras modeladas representando seres humanos (Figura 5). Finalmente, dos kerus llevan decoración plástica particularmente impresionante, en un caso un personaje antropomorfo con cola felina, en otro un animal mítico con atributos de felino y cóndor.

De los 28 kerus $(50 \%)$ que no presentan decoración plástica, 16 forman un grupo bastante homogéneo. Estos llevan cuatro a seis cabezas antropomorfas de perfil (llamadas "cabezas trofeo") sobre su torus $^{1}$ y, más abajo, felinos de perfil, motivos escalonados y cabezas de ave (Figura 5). Los demás kerus $(n=12 ; 21,4 \%)$ llevan iconografía heterogénea y son también algo variados respecto a su morfología.

\section{Ch'alladores}

Una peculiaridad de la colección de Pariti es que contiene un alto número $(n=67)$ de ch'alladores, recipientes con base estrecha y forma cónica. Además, 63 ch'alladores de la colección $(94,0 \%)$ tienen una perforación en su base, por lo tanto estos artefactos son funcionalmente embudos o pacchas (véase Lothrop 1956; también Posnansky 1957:III:36-37), más que vasos para contener líquidos. El exterior de 14 ch'alladores $(20,9 \%)$ tiene como único elemento decorativo una serpiente que se enrosca sobre el vaso dándole la vuelta entre 10 a 15 veces, conformando así la morfología misma del recipiente (Figura 6). La cola está pintada cerca a la base de la pieza, y cerca del borde el cuerpo del animal finaliza en una cabeza modelada.

Doce ch'alladores $(17,9 \%)$ comparten un detalle estructural bastante curioso: tubos cruzados en su interior, fijados a cuatro huecos dispuestos aproximadamente a la mitad del cuerpo (Figura 6). Se desconoce su uso y/o significado. Todos los 


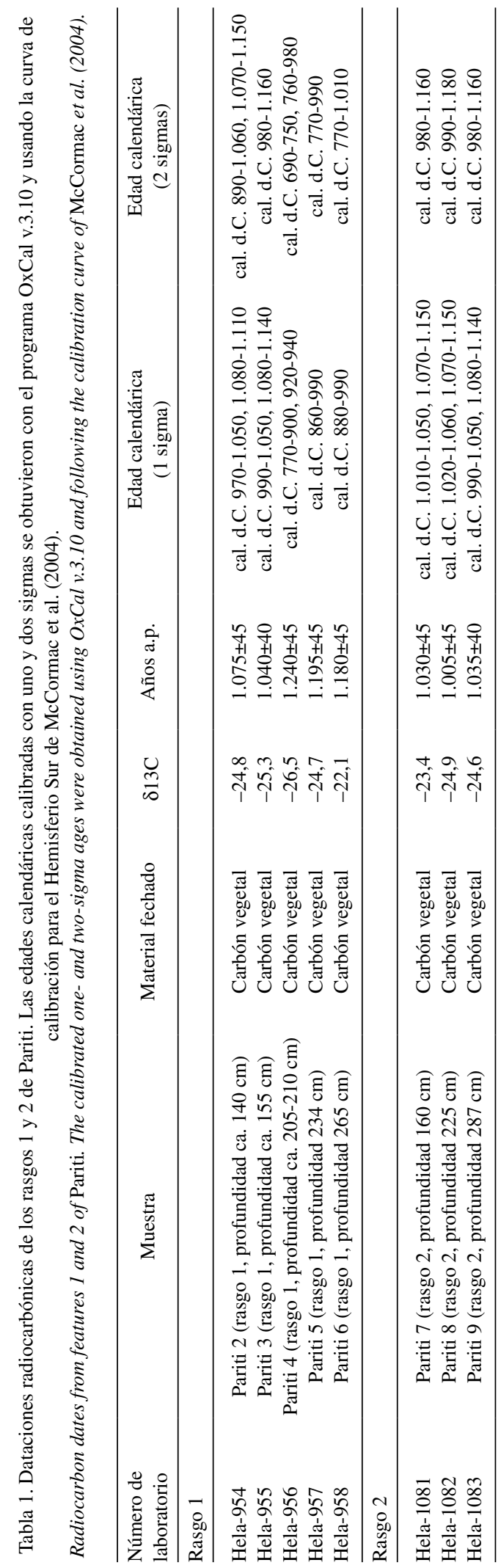

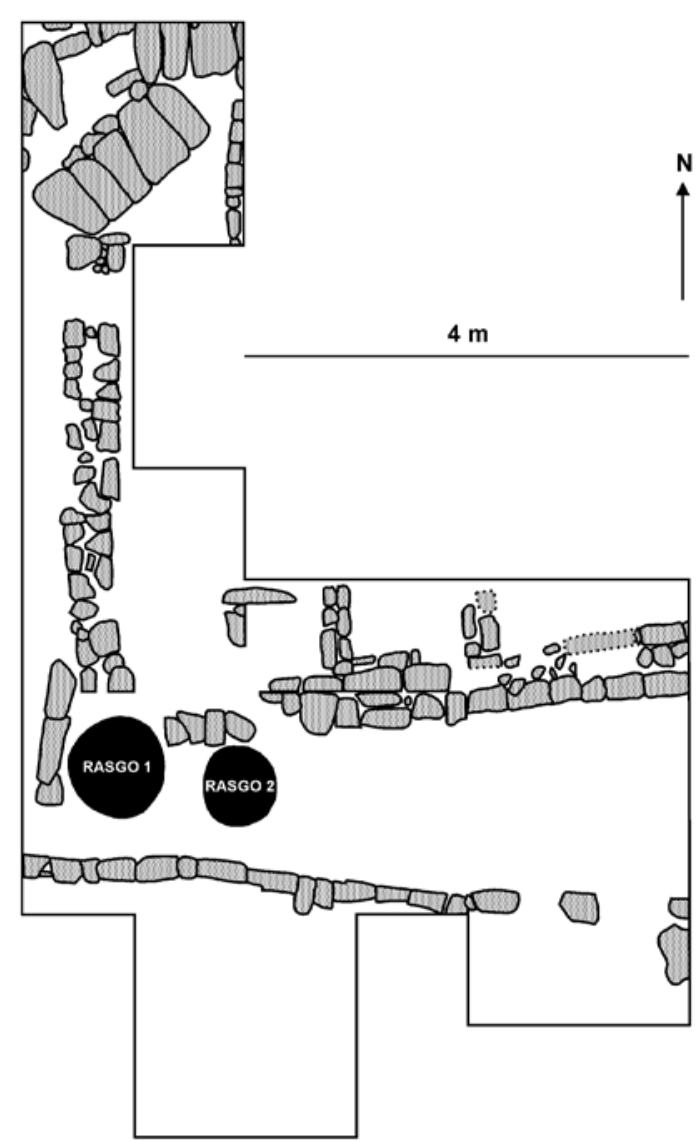

Figura 4. Plano del área de $32 \mathrm{~m}^{2}$ excavada en 2004-2006 en el área central de Pariti. Se destacan los rasgos 1 y 2 en relación a muros o cimientos asociados con dos fases de construcción del período Tiwanaku (dibujo de A. Korpisaari en base a mapas originales A. Korpisaari, M. Pärssinen, J. Sagárnaga y R. Väisänen). Plan of the $32 \mathrm{~m}^{2}$ area excavated in 2004-2006 in the so-called central area of Pariti. Note location of features 1 and 2 in relation to walls or wall foundations that are associated with two Tiwanaku-period building phases (redrawn by A. Korpisaari from original maps by A. Korpisaari, M. Pärssinen, J. Sagárnaga, and $\mathrm{R}$. Väisänen).

ch'alladores de este tipo poseen impresionantes decoraciones pintadas en el exterior, y muchos también en la parte superior de la superficie interna.

Los otros 41 ch'alladores "típicos" $(61,2 \%)$ no tienen decoración plástica ni tubos cruzados en el interior. Su exterior siempre lleva decoración pintada, la que en pocos casos se limita a bandas en blanco, negro y/o anaranjado, pero que en la mayoría de los casos es muy compleja y policroma (Figura 6). El interior de 18 recipientes lleva solo una delgada línea ondulada negra, pero otros seis ch'alladores llevan una compleja decoración interna 
Tabla 2. Número, distribución porcentual y rango y promedio de alturas y diámetros de la boca de vasijas por formas de la colección de Pariti $(\mathrm{n}=435)$.

Number of vessels, percentage, and range and mean of heights and rim diameters by form in the Pariti collection $(n=435)$.

\begin{tabular}{|c|c|c|c|c|}
\hline Forma de vasija & $\begin{array}{c}\text { Cantidad de } \\
\text { piezas }\end{array}$ & $\begin{array}{l}\% \text { de las vasijas } \\
\text { de la colección }\end{array}$ & $\begin{array}{l}\text { Rango y promedio } \\
\text { de alturas } \\
(\mathrm{cm})\end{array}$ & $\begin{array}{l}\text { Rango y promedio de } \\
\text { diámetros de la boca } \\
\qquad(\mathrm{cm})\end{array}$ \\
\hline Keru & 56 & 12,9 & $8,3-30,5$ (promedio 18,5 ) & $6,9-26,2$ (promedio 15,4) \\
\hline Ch'allador & 67 & 15,4 & $11,1-36,5$ (promedio 24,1 ) & $10,2-32,6 \quad$ (promedio 22,3 ) \\
\hline Tazón & 43 & 9,9 & 2,6-7,9 (promedio 6,8) & $6,5-18,4$ (promedio 15,4 ) \\
\hline Escudilla & 82 & 18,9 & 3,2-17,3 (promedio 9,3) & $8,2-49,3 \quad$ (promedio 22,6) \\
\hline Botellón & 26 & 6,0 & $15,7-19,5$ (promedio 18,0 ) & $6,0-9,2 \quad$ (promedio 7,8) \\
\hline Fuente con pedestal & 24 & 5,5 & $9,0-22,0 \quad$ (promedio 14,3 ) & $15,9-33,0 \quad$ (promedio 23,4) \\
\hline Wako retrato & 7 & 1,6 & $12,3-29,5$ (promedio 20,1 ) & 6,7-ca. 15 (promedio 9,7) \\
\hline Tinaja & 7 & 1,6 & $30,3-36,8$ (promedio 33,6 ) & 11,8-ca. 19 (promedio 14,7 ) \\
\hline Sahumador & 6 & 1,4 & $9,5-17,0$ (promedio 11,9 ) & 18,7 -ca. 33 (promedio 21,4 ) \\
\hline Vasija arriñonada & 45 & 10,3 & 4,4-15,4 (promedio 7,2) & 11,0 -ca. 33 (promedio 16,7 ) \\
\hline $\begin{array}{l}\text { Vasija modelada } \\
\text { zoomorfa }\end{array}$ & 20 & 4,6 & $6,2-19,5$ (promedio 13,4 ) & (promedio 6,3) \\
\hline $\begin{array}{l}\text { Vasija modelada } \\
\text { antropomorfa }\end{array}$ & 18 & 4,1 & $12,9-26,2$ (promedio 17,5) & (promedio 5,2) \\
\hline OTRA & 34 & 7,8 & & \\
\hline
\end{tabular}

(Figura 6). Prácticamente todos estos ch'alladores o par de ch'alladores llevan motivos y/o composiciones únicas.

\section{Tazones}

Uno de los tazones de Pariti es una miniatura, los restantes 42 son de tamaño "normal" (diámetro de boca promedio de 15,6 cm). En el sitio-tipo de Tiwanaku, los tazones llevan normalmente decoración principal en el exterior e iconografía secundaria alrededor del borde interior (Janusek 2003:64). Los tazones de Pariti difieren de este patrón: sólo dos tazones de tamaño normal llevan decoración exterior, mientras que 38 llevan decoración interior y tienen exteriores no decorados. El tema decorativo más típico $(n=25)$ es dos o tres cabezas de ave invertidas cerca del borde y un par de bandas horizontales más abajo (Figura 7). Otro tema popular $(n=10)$ se basa en motivos en forma de " $T$ " alternando con rombos (Figura 7).

\section{Escudillas}

Las 82 escudillas de la colección de Pariti son de tres categorías de tamaño: pequeñas $(n=29$; $35,4 \%)$, grandes $(n=50 ; 61,0 \%)$ y muy grandes $(n=3 ; 3,7 \%)$. Las escudillas pequeñas tienen diámetro de boca promedio de $12,0 \mathrm{~cm}$, altura promedio de $5,5 \mathrm{~cm}$ y poseen decoración pintada - felinos de perfil $(n=8)$, cabezas de felino $(n=6)$ (Figura 7), motivos escalonados $(n=4)$ o rayas negras simples $(n=4)$ - solamente en el borde interior.

Las escudillas grandes tienen diámetro del borde promedio de $27,2 \mathrm{~cm}$ y altura promedio de $11,2 \mathrm{~cm}$. El borde interior $-4,5$ a 7,2 $\mathrm{cm}$ de ancho- siempre lleva decoración pintada. Casi toda la superficie externa de la mayoría de estas piezas lleva decoración. Las escudillas grandes recuperadas en el rasgo 1 están decoradas de forma bastante homogénea (Figura 7): típicamente, en el borde interior cuatro a seis felinos de perfil alternan con motivos escalonados rematados por una cabeza de ave, mientras que el exterior lleva tres felinos más grandes (y, en muchos casos, motivos escalonados rematados por una cabeza de ave) o -menos frecuentemente- tres "Personajes de Perfil" (véase Korpisaari y Pärssinen 2011; Villanueva 2007). Las escudillas grandes del rasgo 2 llevan iconografía más heterogénea, con composiciones variadas y algunos motivos atípicos. Dos escudillas grandes recuperadas en el rasgo 2 también poseen una acanaladura, rasgo que no ha sido reportado antes 

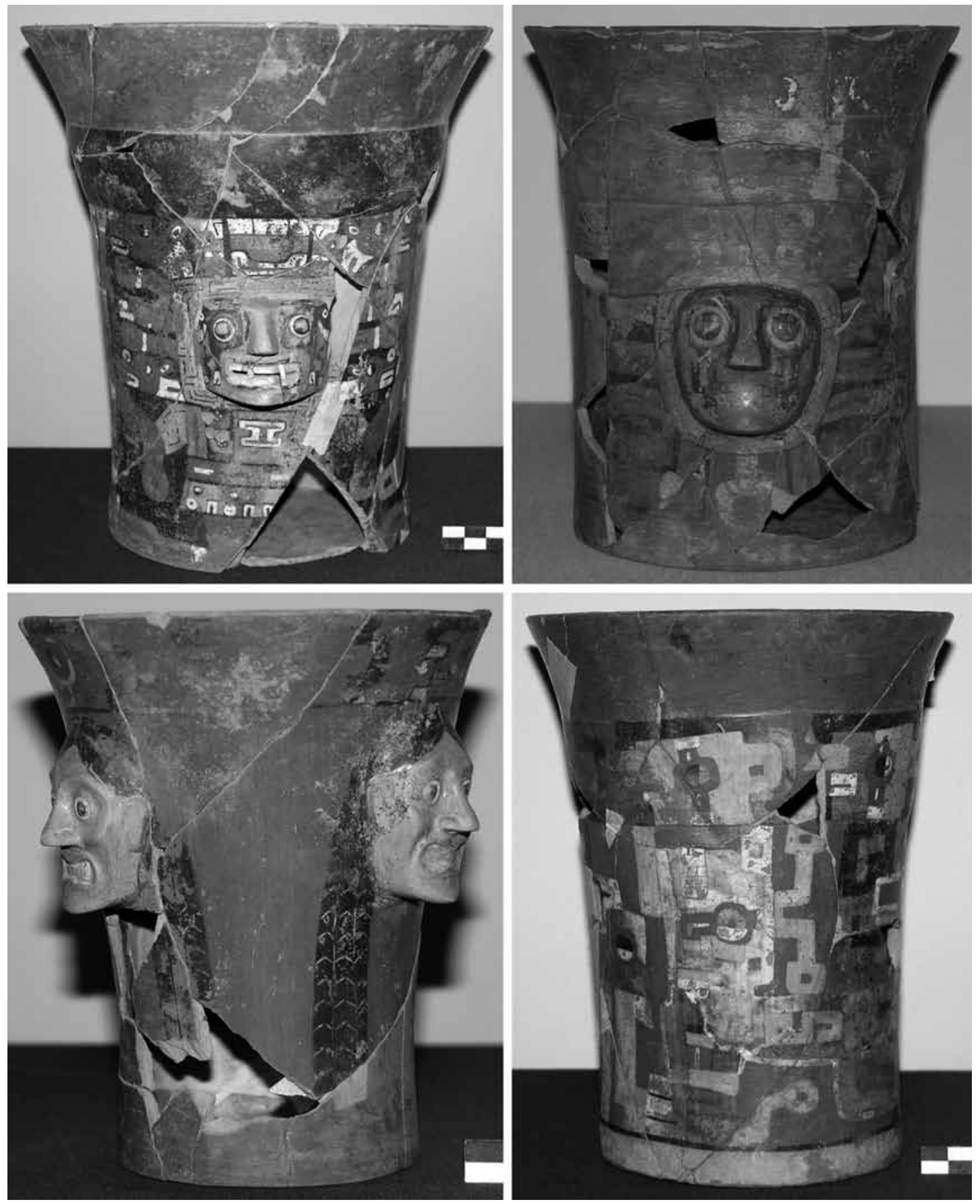

Figura 5. Kerus de la colección de Pariti. Arriba, de izquierda a derecha: PRT 00154 (altura 23,1 cm) y 00479 (altura 24,2 cm). Abajo, de izquierda a derecha: PRT 00088 (altura 13,8 cm) y 00230 (altura 21,5 cm). Nótese que los ceramios no aparecen a la misma escala en ninguna de las Figuras 5-12 (fotos A. Korpisaari).

Kerus of the Pariti collection. Above, from left to right: PRT 00154 (height $23.1 \mathrm{~cm}$ ) and 00479 (height $24.2 \mathrm{~cm}$ ). Below, from left to right: PRT 00088 (height $13.8 \mathrm{~cm}$ ) and 00230 (height $21.5 \mathrm{~cm}$ ). Note that the vessels are not portrayed in the same scale in Figures 5-12 (photos A. Korpisaari). 

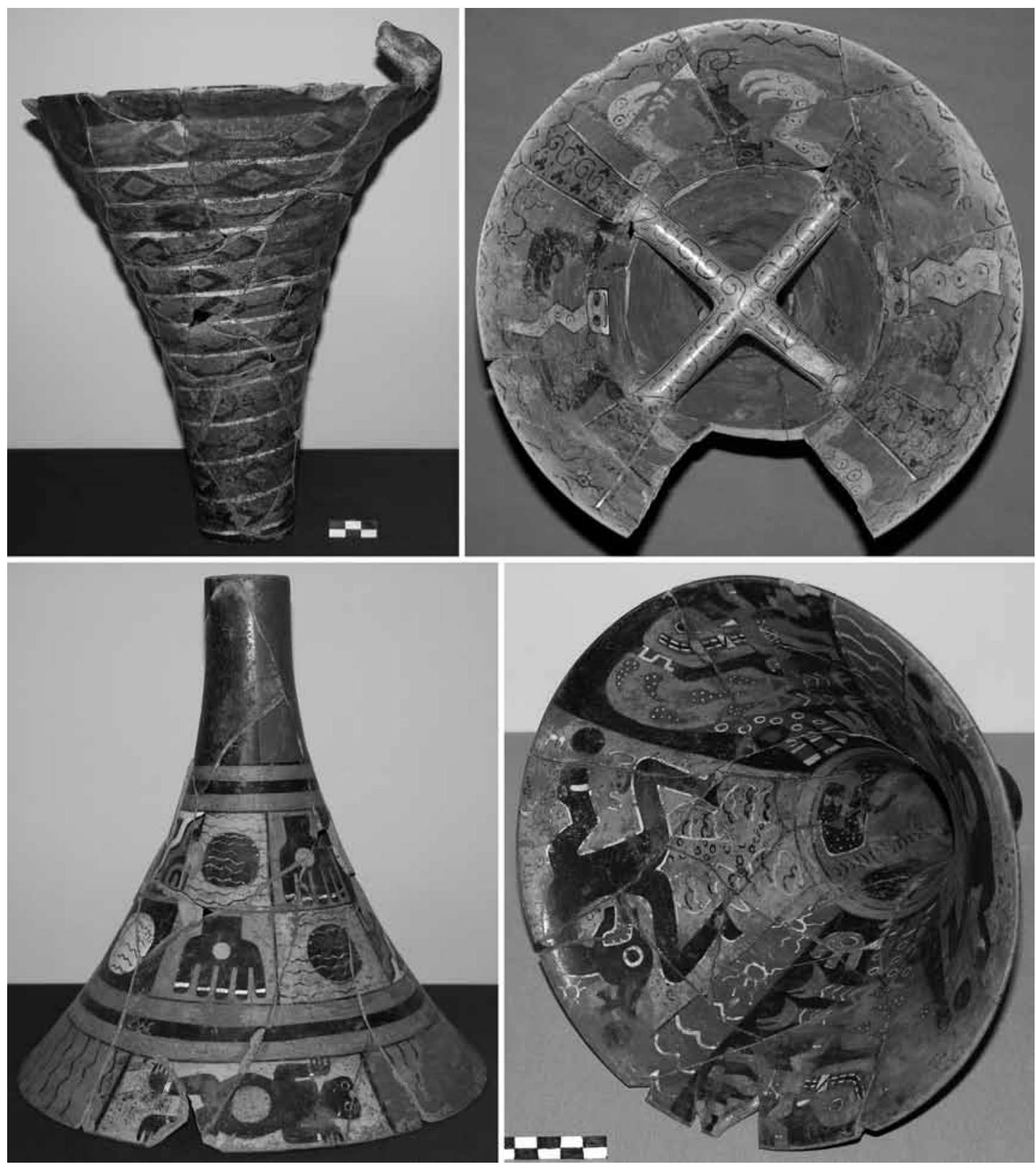

Figura 6. Ch'alladores de los rasgos 1 y 2 de Pariti. Arriba, de izquierda a derecha: el ch'allador ofídico PRT 00278 (altura 27,6 $\mathrm{cm}$ ) y el interior de la pieza PRT 00517 (nótense los tubos cruzados) (diámetro del borde 25,0 cm). Abajo, de izquierda a derecha: PRT 00264 (boca abajo) (altura 26,0 cm) y el interior del ch'allador PRT 00111 (diámetro del borde 24,5 cm) (fotos A. Korpisaari). Ch'alladores of features 1 and 2. Above, from left to right: the snake ch'allador PRT 00278 (height $27.6 \mathrm{~cm}$ ) and the interior of the piece PRT 00517 (note the crosswise tubes) (rim diameter $25.0 \mathrm{~cm}$ ). Below, from left to right: PRT 00264 (upside down) (height $26.0 \mathrm{~cm}$ ) and the interior of the ch'allador PRT 00111 (rim diameter $24.5 \mathrm{~cm}$ ) (photos A. Korpisaari).

para la cerámica tiwanakota (Figura 7). Uno de estos últimos recipientes también lleva dos asas.

Los diámetros de la boca de las tres escudillas más grandes de la colección de Pariti miden 36,2, 42,0 y $49,3 \mathrm{~cm}$, respectivamente, y sus alturas varían entre 13,2 y 17,3 cm. En todos los casos el borde interior lleva decoración pintada, mientras que el exterior no es decorado. Las dos escudillas más grandes llevan dos asas cada una, la tercera posee una acanaladura. 

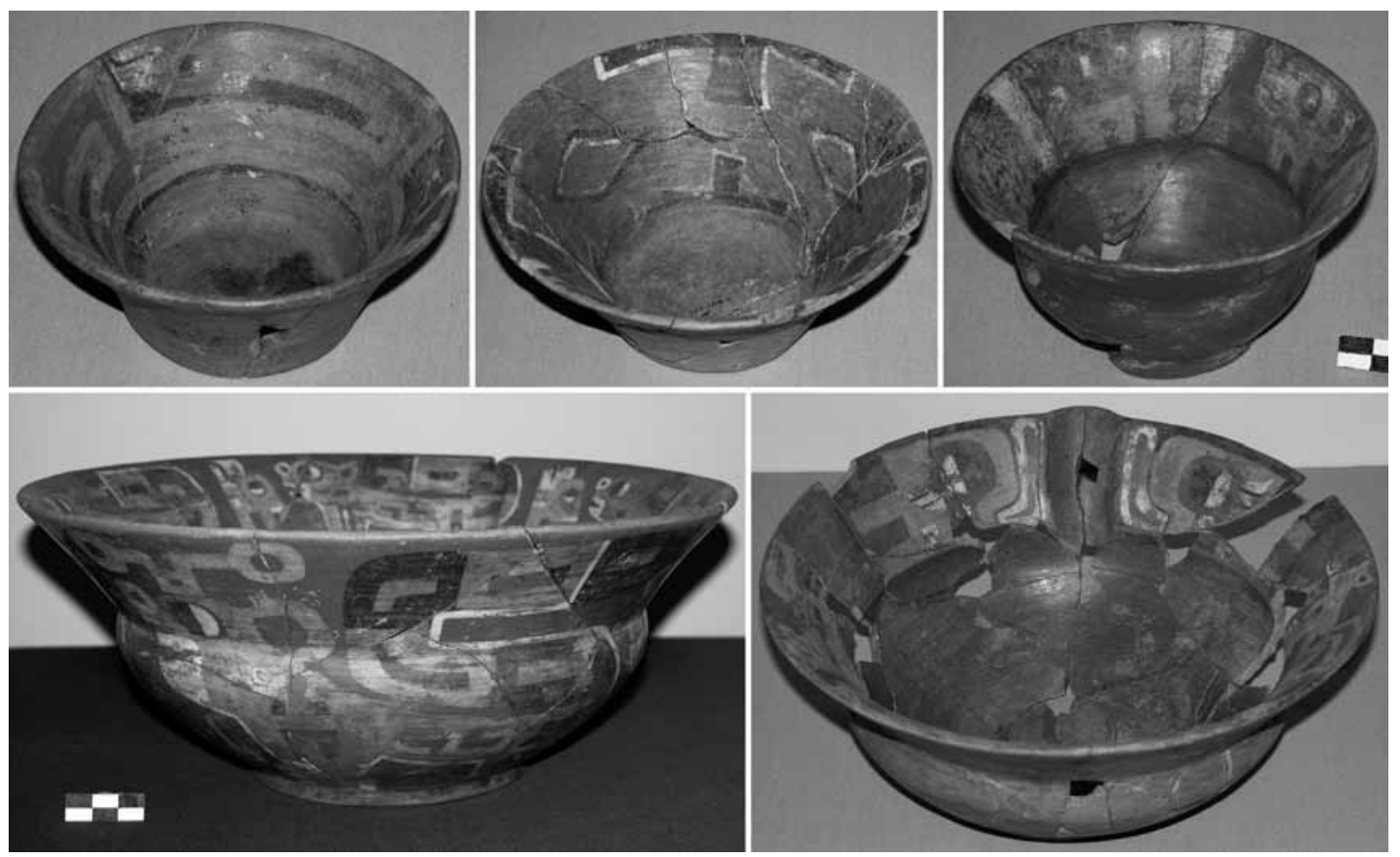

Figura 7. Tazones y escudillas de la colección de Pariti. Arriba, de izquierda a derecha: los tazones PRT 00463 (diámetro del borde 14,2 cm) y 00459 (diámetro del borde 17,9 cm) y la escudilla pequeña PRT 00453 (diámetro del borde 12,0 cm). Abajo, de izquierda a derecha: las escudillas grandes PRT 00115 (altura 11,9 cm) y 00439 (diámetro del borde 29,3 cm) (fotos A. Korpisaari). Tazones and escudillas of the Pariti collection. Above, from left to right: the tazones PRT 00463 (rim diameter $14.2 \mathrm{~cm}$ ) and 00459 (rim diameter $17.9 \mathrm{~cm}$ ) and the small escudilla PRT 00453 (rim diameter $12.0 \mathrm{~cm})$. Below, from left to right: the large escudillas PRT 00115 (height $11.9 \mathrm{~cm}$ ) and 00439 (rim diameter $29.3 \mathrm{~cm}$ ) (photos A. Korpisaari).

\section{Botellones}

Los rasgos 1 y 2 contenían un total de 26 botellones. Todos llevan decoración pintada en su exterior, aproximadamente la mitad también en el borde interior. La decoración externa típicamente consiste en dos zonas separadas por una o varias bandas en anaranjado y/o negro. Muchas veces, ambas zonas llevan dos o tres felinos de perfil, los de la zona inferior frecuentemente alternando con motivos escalonados rematados en una cabeza de ave (Figura 8). No obstante, cinco botellones llevan los "Personajes de Perfil" y otras pocas piezas llevan iconografía más variada.

\section{Fuentes con pedestal}

Encontramos 24 fuentes con pedestal en Pariti. Doce $(50 \%)$ de estas son "típicas" en el sentido de que no poseen ni decoración plástica ni pitón (Figura 9). Con la excepción de dos piezas de cerámica negra, el exterior de las fuentes con pedestal "típicas" siempre lleva decoración pintada; en tres casos, toda la superficie externa está decorada de esa manera. De las 12 fuentes con pedestal "menos típicas", seis piezas bastante pequeñas llevan iconografía serpentina parcialmente modelada. Existen tres grandes fuentes con pedestal que no llevan ninguna decoración pintada, pero cada una posee una figurilla modelada en el borde exterior. Finalmente, el pedestal de tres recipientes de esta forma es un "wako retrato" (Figura 9).

\section{Wako retratos}

En la colección de Pariti hay también siete wako retratos "típicos", todos provenientes del rasgo 1 y que parecen representar a varones (Figura 10). Este grupo está compuesto por dos pares y tres piezas individuales. Respecto al tamaño y la morfología de los recipientes y las combinaciones de adornos personales, cortes de cabello y/o gorros que los personajes llevan, las piezas de esta categoría son muy heterogéneas. Dos wako retratos tienen o tenían pitón. 

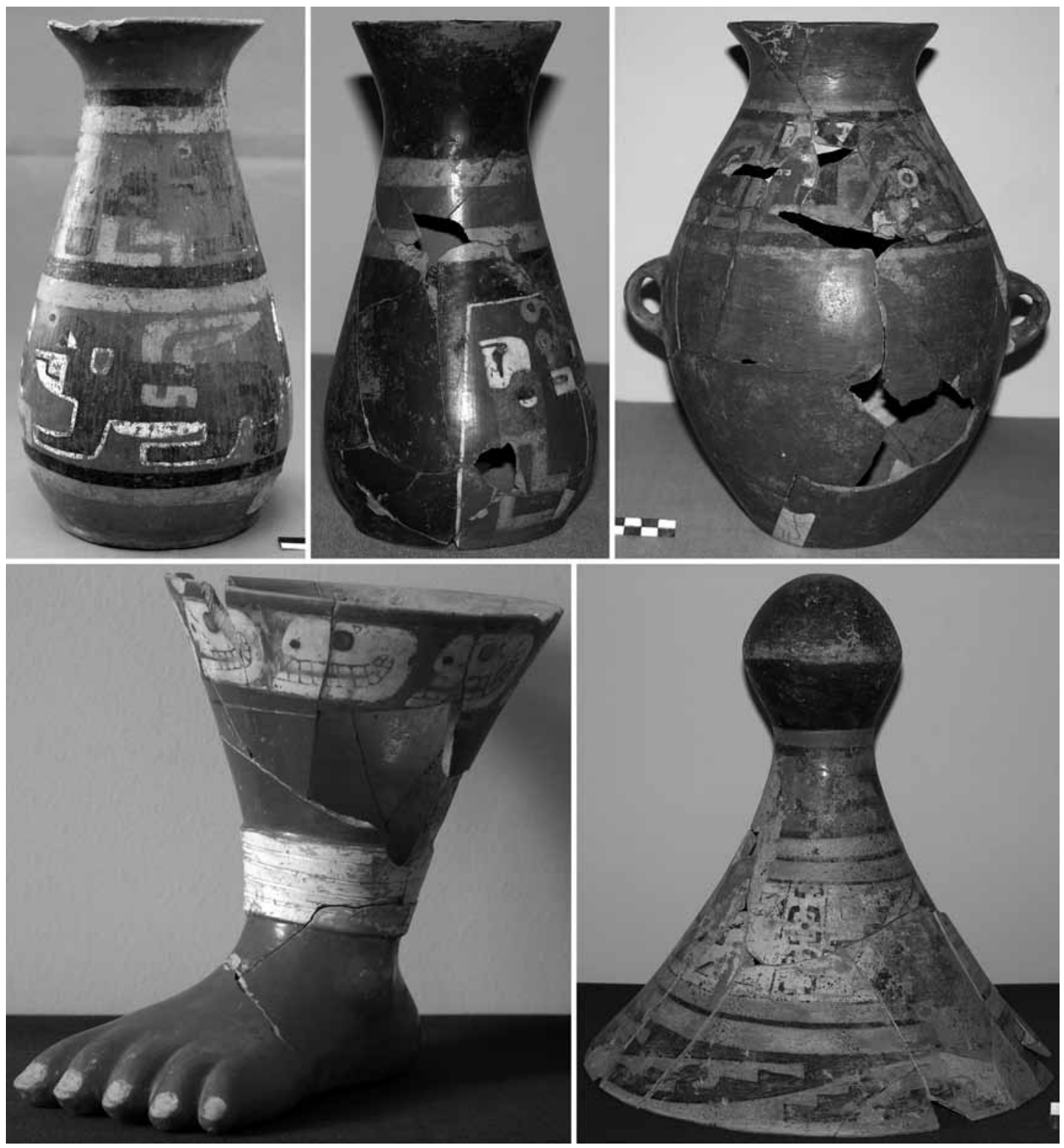

Figura 8. Recipientes de varias formas de los rasgos 1 y 2 de Pariti. Arriba, de izquierda a derecha: los botellones PRT 00095 (altura $17,2 \mathrm{~cm}$ ) y 00486 (altura 16,4 cm) y la tinaja PRT 00505 (altura 30,3 cm). Abajo, de izquierda a derecha: el vaso pie PRT 00160 (altura 14,3 cm) y el vaso con base esférica PRT 00156 (boca abajo) (altura 20,6 cm) (fotos A. Korpisaari).

Vessels of several forms of the Pariti collection. Above, from left to right: the bottles PRT 00095 (height $17.2 \mathrm{~cm}$ ) and 00486 (height $16.4 \mathrm{~cm}$ ) and the tinaja PRT 00505 (height $30.3 \mathrm{~cm}$ ). Below, from left to right: the foot-shaped beaker PRT 00160 (height $14.3 \mathrm{~cm})$ and the globular-based beaker PRT 00156 (upside down) (height $20.6 \mathrm{~cm}$ ) (photos A. Korpisaari).

\section{Tinajas}

Los rasgos 1 y 2 de Pariti contenían fragmentos de al menos siete tinajas, pero pudimos reconstruir sólo dos de estos grandes ceramios más o menos completamente. Ambas tinajas reconstruidas tienen un cuello bastante corto y un par de asas verticales, y llevan una banda ancha de motivos escalonados y cabezas de ave en la parte superior del cuerpo (Figura 8). 

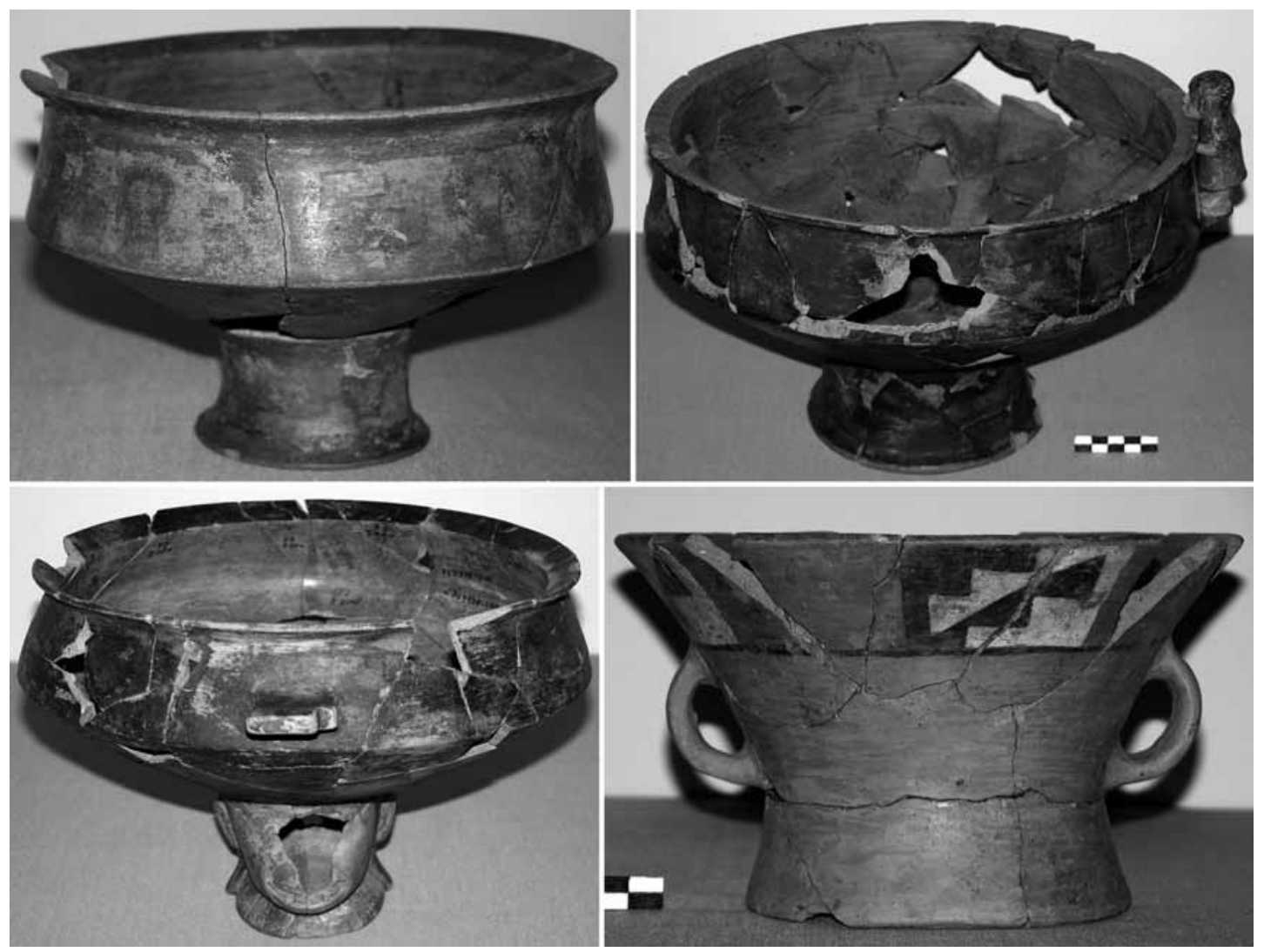

Figura 9. Fuentes con pedestal y sahumadores de la colección de Pariti. Arriba, de izquierda a derecha: las fuentes con pedestal PRT 00525 (altura 11,2 cm) y 00530 (diámetro del borde 32,0 cm). Abajo, de izquierda a derecha: la fuente con pedestal PRT 00309 (nótese el pedestal atípico) (diámetro del borde 23,0 cm) y el sahumador PRT 00539 (altura 11,3 cm) (fotos A. Korpisaari). Pedestal bowls and sahumadores of the Pariti collection. Above, from left to right: the pedestal bowls PRT 00525 (height 11.2 $\mathrm{cm}$ ) and 00530 (rim diameter $32.0 \mathrm{~cm}$ ). Below, from left to right: the pedestal bowl PRT 00309 (note the atypical pedestal) (rim diameter $23.0 \mathrm{~cm}$ ) and the sahumador PRT 00539 (height $11.3 \mathrm{~cm}$ ) (photos A. Korpisaari).

\section{Sahumadores}

La colección de Pariti incluye seis sahumadores, siendo cinco de tamaño más o menos estándar (Figura 9), y el sexto más grande. Todos los sahumadores tienen dos asas verticales. Tres piezas llevan decoración pintada tanto en el exterior como en el interior, una sólo en el exterior y una (la grande) sólo en el interior. El último sahumador no lleva decoración.

Además de formas de vasijas tiwanakotas típicas, la colección de piezas cerámicas de los rasgos 1 y 2 incluye docenas de vasijas cuyas formas son menos comunes, o incluso eran inéditas o desconocidas antes de nuestras investigaciones en Pariti. Vale la pena mencionar cuatro vasos con base en forma de pies, y un par de vasos con base esférica (Figura 8). La colección de Pariti también incluye 45 vasijas de la forma poco conocida que hemos denominado "arriñonada" y 38 vasijas modeladas: 20 zoomorfas y 18 antropomorfas.

\section{Vasijas arriñonadas}

Esta forma de recipiente tiwanakota no había sido descrita en la literatura arqueológica antes del descubrimiento de los rasgos 1 y 2 de Pariti. Estas piezas tienen forma oblonga, con una "depresión" central bastante baja a ambos lados de la longitud mayor, por lo que vistas desde arriba se asemejan al número 8 (Figura 11). Las vasijas arriñonadas típicas tienen base bastante plana. Sin embargo, la colección también incluye recipientes más grandes de base más redondeada $(n=8 ; 17,8 \%)$. Además, hay una tercera variedad de vasijas arriñonadas de base anular $(n=5 ; 11,1 \%)$. 

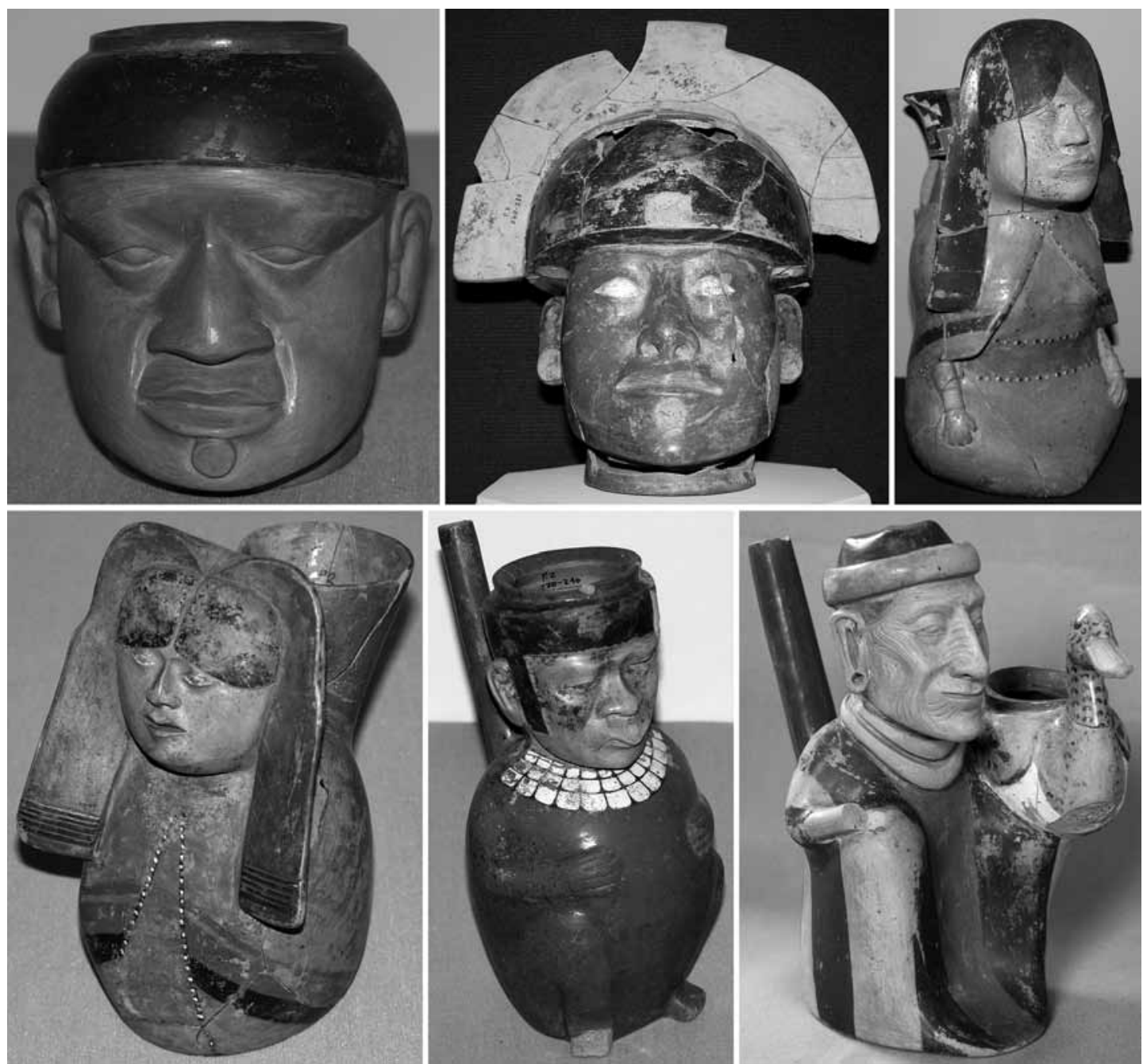

Figura 10. Cerámica modelada antropomorfa del rasgo 1 de Pariti. Arriba, de izquierda a derecha: los wako retratos PRT 00075 (altura 12,5 cm) y 00188 (altura 29,5 cm) y la representación femenina de cuerpo entero PRT 00184 (altura 20,4 cm). Abajo, de izquierda a derecha: la representación femenina de cuerpo entero PRT 00181 (altura 14,4 cm) y las representaciones masculinas de cuerpo entero PRT 00074 (altura 20,5 cm) y 00072 (altura 13,0 cm) (fotos A. Korpisaari).

Anthropomorphic sculptural pottery from feature 1 of Pariti. Above, from left to right: the portrait vessels PRT 00075 (height 12.5 $\mathrm{cm}$ ) and 00188 (height $29.5 \mathrm{~cm}$ ) and the female effigy vessel PRT 00184 (height $20.4 \mathrm{~cm}$ ). Below, from left to right: the female effigy vessel PRT 00181 (height $14.4 \mathrm{~cm}$ ) and the male effigy vessels PRT 00074 (height $20.5 \mathrm{~cm}$ ) and 00072 (height $13.0 \mathrm{~cm}$ ) (photos A. Korpisaari).

Característicamente, las vasijas arriñonadas pequeñas de base plana llevan decoración pintada sólo en el exterior. Sus motivos más comunes son cabezas antropomorfas de perfil $(n=9)$, cabezas de ave $(n=6)$ y volutas continuas ( $n=4)$ (Figura 11$)$. Menos típicamente, el exterior e interior de las vasijas arriñonadas pequeñas están divididos en cuatro zonas de igual tamaño, dos de color rojo y otras dos anaranjadas $(n=6)$ (Figura 11). De los ocho recipientes grandes con base redonda, cuatro llevan decoración relativamente fina sólo en el exterior, dos sólo en su interior, y los últimos dos en ambas caras.

Como Väisänen (2008:83) ha notado, recipientes morfológicamente similares a las vasijas arriñonadas de Pariti se manufacturan actualmente en Toconce, en el norte de Chile. En su estudio de la producción alfarera en esta comunidad, Varela (2002:247, Figura 20j-1) señala que estas vasijas son pequeñas (con alturas entre 5-6 cm y diámetros 


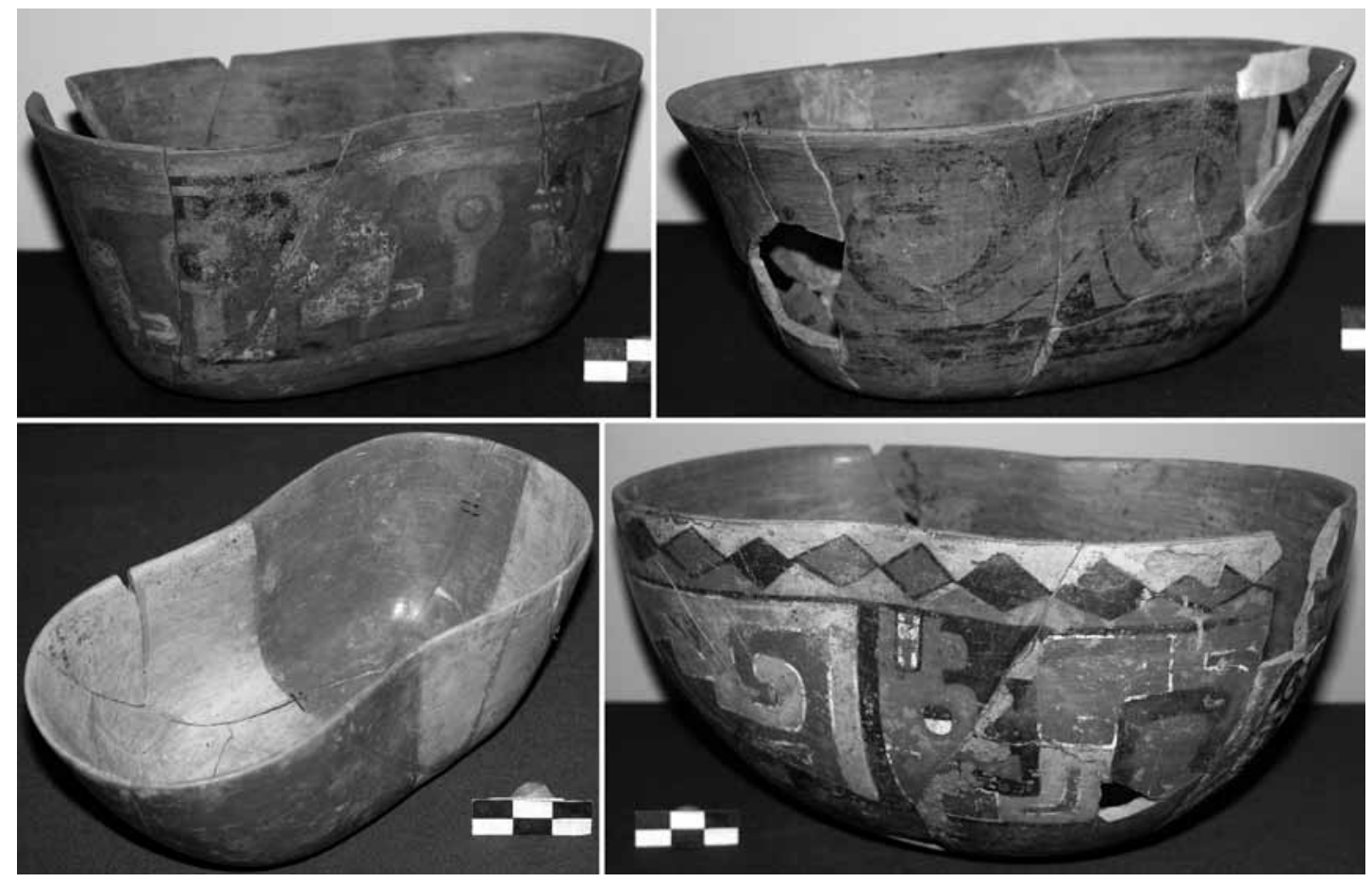

Figura 11. Vasijas arriñonadas de la colección de Pariti. Arriba, de izquierda a derecha: PRT 00191 (diámetro máximo del borde $16,0 \mathrm{~cm}$ ) y 00193 (diámetro máximo del borde 17,2 cm). Abajo, de izquierda a derecha: PRT 00107 (diámetro máximo del borde $15,8 \mathrm{~cm}$ ) y 00109 (nótese la base bastante redondeada) (diámetro máximo del borde 21,1 cm) (fotos A. Korpisaari).

Kidney-shaped bowls of the Pariti collection. Above, from left to right: PRT 00191 (maximum rim diameter $16.0 \mathrm{~cm}$ ) and 00193 (maximum rim diameter $17.2 \mathrm{~cm}$ ). Below, from left to right: PRT 00107 (maximum rim diameter $15.8 \mathrm{~cm}$ ) and 00109 (note the rather rounded base) (maximum rim diameter $21.1 \mathrm{~cm}$ ) (photos A. Korpisaari).

de la boca entre 11-14 cm), "de forma arriñonada", llamadas tinkero o mate, y sirven como parte de mesas rituales.

\section{Vasijas modeladas zoomorfas}

Los 20 recipientes de esta categoría tienen pitón. Catorce (70\%) representan patos del Lago Titicaca (Figura 12). De las otras seis, tres representan llamas recostadas, dos algún tipo de ave de rapiña, posiblemente el águila arpía amazónica (Korpisaari et al. 2009) y la última una nutria o lagartija (Figura 12).

\section{Vasijas modeladas antropomorfas}

Nueve de las 18 piezas que componen esta categoría (50\%) representan mujeres sentadas o en cuclillas (Figura 10). Ocho de estas vasijas forman pares, tres idénticos y uno no idéntico. Además, las nueve vasijas son bastante uniformes respecto a su morfología y decoración: todas las mujeres tienen cabello largo con raya en el medio, y llevan un vestido largo y una manta decorada. Con excepción de los brazaletes en un par de vasijas, estas mujeres no llevan joyas u otros adornos personales.

Además de las nueve piezas en forma de mujeres, la colección de Pariti incluye nueve vasijas efigies que representan varones de cuerpo entero (Figura 10). Entre estos recipientes hay dos $\operatorname{pares}^{2} \mathrm{y}$ un grupo de cuatro vasijas bastante similares entre sí. No obstante, este grupo es más heterogéneo que el de las vasijas en forma de mujeres. Todos los varones representados llevan adornos personales -v. gr., tembetás, collares, brazaletes y/o tobilleras- $y$ tienen pitón (que ninguna vasija en forma de mujer tiene).

\section{Aspectos técnicos}

La arqueóloga Soledad Fernández investigó 227 ceramios de Pariti, distinguiendo ocho pastas, que fueron clasificadas en un grupo de pastas finas y otro de pastas gruesas. El primer grupo es más 

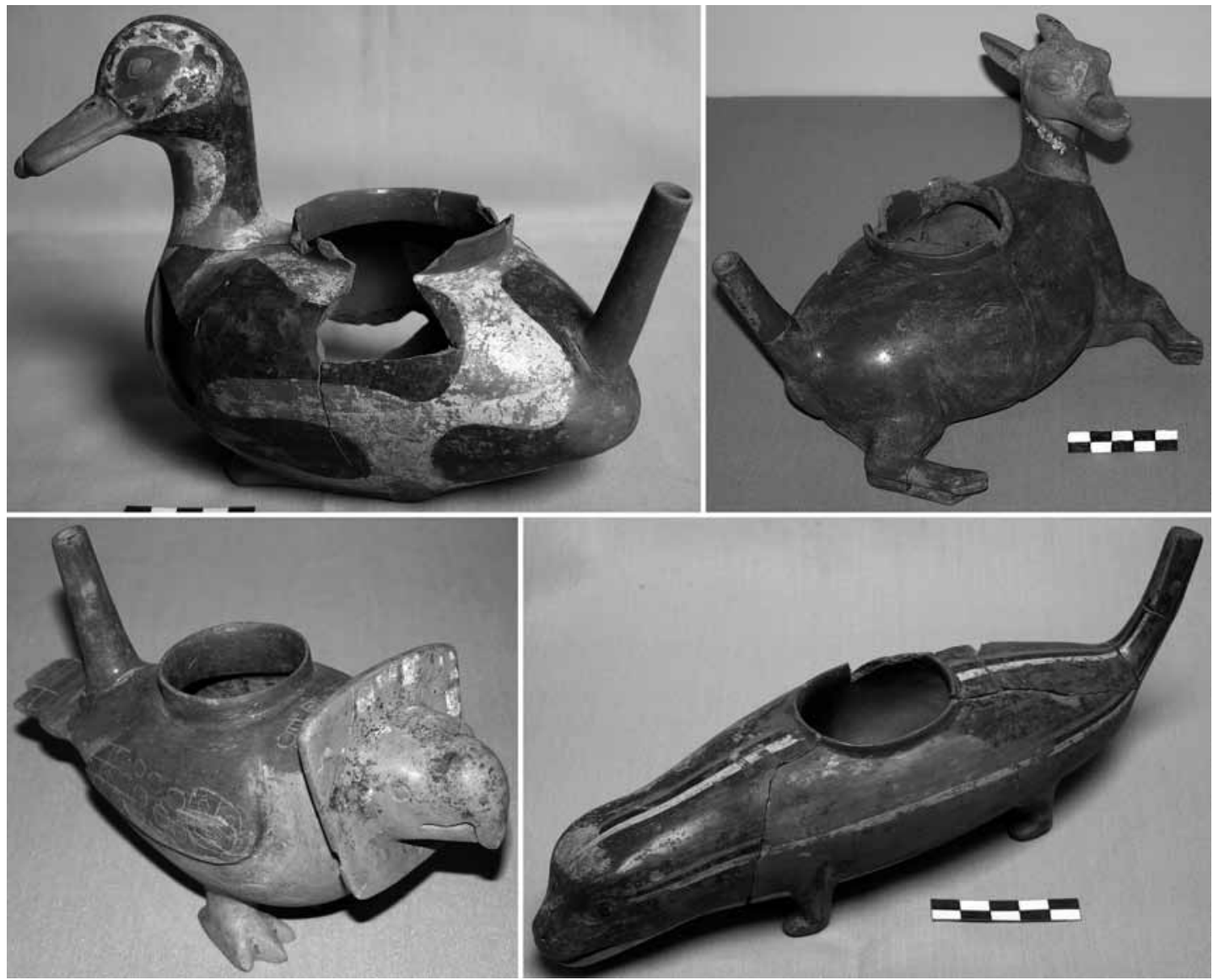

Figura 12. Cerámica modelada zoomorfa de los rasgos 1 y 2 de Pariti. Arriba, de izquierda a derecha: la palmípeda PRT 00102 (altura 18,3 cm) y la llama PRT 00490 (altura 14,2 cm). Abajo, de izquierda a derecha: el ave de presa PRT 00081 (altura 11,3 cm) y la nutria o lagartija PRT 00089 (altura 6,2 cm) (fotos A. Korpisaari).

Zoomorphic effigy vessels of the Pariti collection. Above, from left to right: the waterfowl PRT 00102 (height $18.3 \mathrm{~cm}$ ) and the llama PRT 00490 (height $14.2 \mathrm{~cm}$ ). Below, from left to right: the bird of prey PRT 00081 (height $11.3 \mathrm{~cm}$ ) and the otter or lizard PRT 00089 (height $6.2 \mathrm{~cm}$ ) (photos A. Korpisaari).

numeroso, y su utilización permitió la elaboración de vasijas con paredes delgadas y tamaños pequeños y medianos, mientras que el segundo grupo se encuentra preferentemente asociado a piezas grandes. El trabajo de Fernández sugiere que la cerámica de Pariti es relativamente homogénea en términos de pasta. La predominancia de inclusiones de arena, cuarzo y mica, comunes en la cerámica tiwanakota del altiplano central, sugiere la utilización de una sola fuente de arcilla (Fernández 2006). Así, casi todas las vasijas de la colección de Pariti habrían sido manufacturadas en el área nuclear Tiwanaku. Aún no sabemos si los ceramios fueron manufacturados en Pariti, o en otro lugar. Sin embargo, el alto grado de habilidad tecnológica y decorativa involucrada sugiere una producción alfarera especializada.

\section{Disquisiciones}

Los rasgos 1 y 2 de Pariti eran ofrendas religiosas, bolsones en que los fragmentos de recipientes quebrados intencionalmente se depositaban después de una ceremonia/fiesta. El inmenso número de recipientes (al menos 435), y la calidad artística y técnica excepcional de muchas de las piezas, sugieren que se trataba de un evento de proporción e importancia mayúsculas. Esta conclusión se apoya también en la presencia de huesos de al menos 33 camélidos en ambos rasgos, entremezclados con los 
fragmentos cerámicos (Callisaya 2005, 2006). Es probable que estos animales se hayan sacrificado durante o poco antes de la ceremonia en que se quebraron los recipientes, y que se consumiera su carne durante las celebraciones.

Janusek (2003:Figura 3.27, 2004:Figura 3.2) clasifica las formas principales de vasijas tiwanakotas en cuatro categorías: vasijas de almacenamiento, vasijas para preparar comida, vasijas de servir y vasijas ceremoniales. En la colección de Pariti hay solamente siete vasijas de almacenamiento (tinajas) ${ }^{3}$ y ninguna vasija para preparar comida. Más del $70 \%$ de los ceramios de la colección son vasijas de servir (a esta categoría pertenecen los kerus, vasijas y botellones, usados para las bebidas; y los tazones, escudillas y vasijas arriñonadas, usados para las comidas, entre otras formas). Otra categoría bien representada (ca. 24\%) en la colección de Pariti es la de vasijas ceremoniales, conformada por fuentes con pedestal, wako retratos, sahumadores y ch'alladores.

Este análisis de las características funcionales de los ceramios de la colección de Pariti indica que parece tratarse de una ofrenda producto de actividades ceremoniales de consumo público. Después del evento se rompían las vasijas usadas y se enterraban sus fragmentos. No se incluían vasijas para preparar la comida en estos depósitos de ofrendas, posiblemente por no tratarse de cerámica suntuaria. Llama la atención que una de las formas clásicas de la cerámica ceremonial tiwanakota, el incensario que suele tener la testa de un felino u otro animal como adorno en el borde, esté ausente en ambos rasgos. Creemos que esta forma fue usada en las ceremonias, pues en el rasgo 2 encontramos un fragmento de borde de un incensario. Sin embargo, por alguna razón (tal vez porque eran instrumentos del oficiante) los incensarios usados no se rompían intencionalmente, o no se solían enterrar sus tiestos.

Es posible que periódicamente (según un calendario religioso, o para marcar ciertos eventos sociopolíticos) se organizara en Pariti una ceremonia y/o fiesta mayor. Eso explicaría tanto la formación de los rasgos 1 y 2 como la del bolsón lleno de cerámica fina situado ca. 40 metros al sur de los mismos. Pensamos que este último bolsón, encontrado por unos comunarios en la década de 1990, era un "tercer rasgo" parecido a los dos estudiados arqueológicamente, aunque de contenido algo distinto. Otra posibilidad es que los rasgos 1 y 2 sean una ofrenda terminal, coincidente con el abandono de la construcción de muros de doble hilera situada inmediatamente al norte del par de rasgos. La esquina entre las dos secciones de muro reveladas parece parcialmente desmontada (¿para acomodar los dos bolsones de ofrendas?), lo que apoyaría esta segunda interpretación, la que está también apuntalada por las dataciones bastante tardías de los rasgos 1 y 2 . Es posible que las condiciones políticas y económicas de aquel momento señalasen la inminente caída del estado altiplánico y que por ese motivo se interpusieran "rogativas" materializadas en las ofrendas de Pariti. De cualquier manera, el "sacrificio" simultáneo de tanta cerámica y animales tras un posible evento ceremonial en la pequeña isla de Pariti, nos hace pensar en su carácter sacro para el Estado tiwanakota, o al menos para los habitantes locales de la porción menor del Titicaca.

Los artefactos de oro descubiertos en Pariti durante los siglos XX y XXI refuerzan nuestras interpretaciones sobre la sacralidad de la isla. La tumba que Bennett (1936:448-454) descubrió y que contenía 23 objetos de oro constituye un hallazgo excepcional. Además, la familia Pacheco encontró un keru de oro de ca. $20 \mathrm{~cm}$ de altura (véase Bennett 1936:Figura 31; Posnansky 1957:III:Plancha LXXXIX A a) y varias placas pequeñas de oro repujado en otra tumba en la isla (Bennett 1936:448). Nuestras excavaciones documentaron algunas láminas delgadas de oro en los niveles inferiores del rasgo 2 (Figura 13).

La cerámica de Pariti difiere en ciertos aspectos del material del sitio de Tiwanaku, Lukurmata y otros sitios tiwanakotas investigados. Muchos de los motivos y temas iconográficos pintados sobre los ch'alladores de los rasgos 1 y 2 no habían sido documentados antes. Además, las composiciones con iconos tiwanakotas típicos sobre muchas escudillas y kerus de Pariti difieren ligeramente de las de la "capital", y los tazones pariteños llevan decoración en el interior, es decir, en la cara "equivocada". $\mathrm{Al}$ respecto, Väisänen (2008:118) sugiere que la cerámica de los rasgos 1 y 2 de Pariti representa un subestilo del estilo tiwanakota general. Para Patiño y Villanueva (2009) se trataría más bien de subconjuntos manufacturados con fines estrictamente rituales, en concordancia con el significado sacro y la función de las diversas formas cerámicas y repertorios iconográficos. Sea como fuere, la cerámica de la colección de Pariti tiene algunos rasgos en común con el estilo Lukurmata definido por Janusek (2003:80, 2004:190-194, 2008:204). 

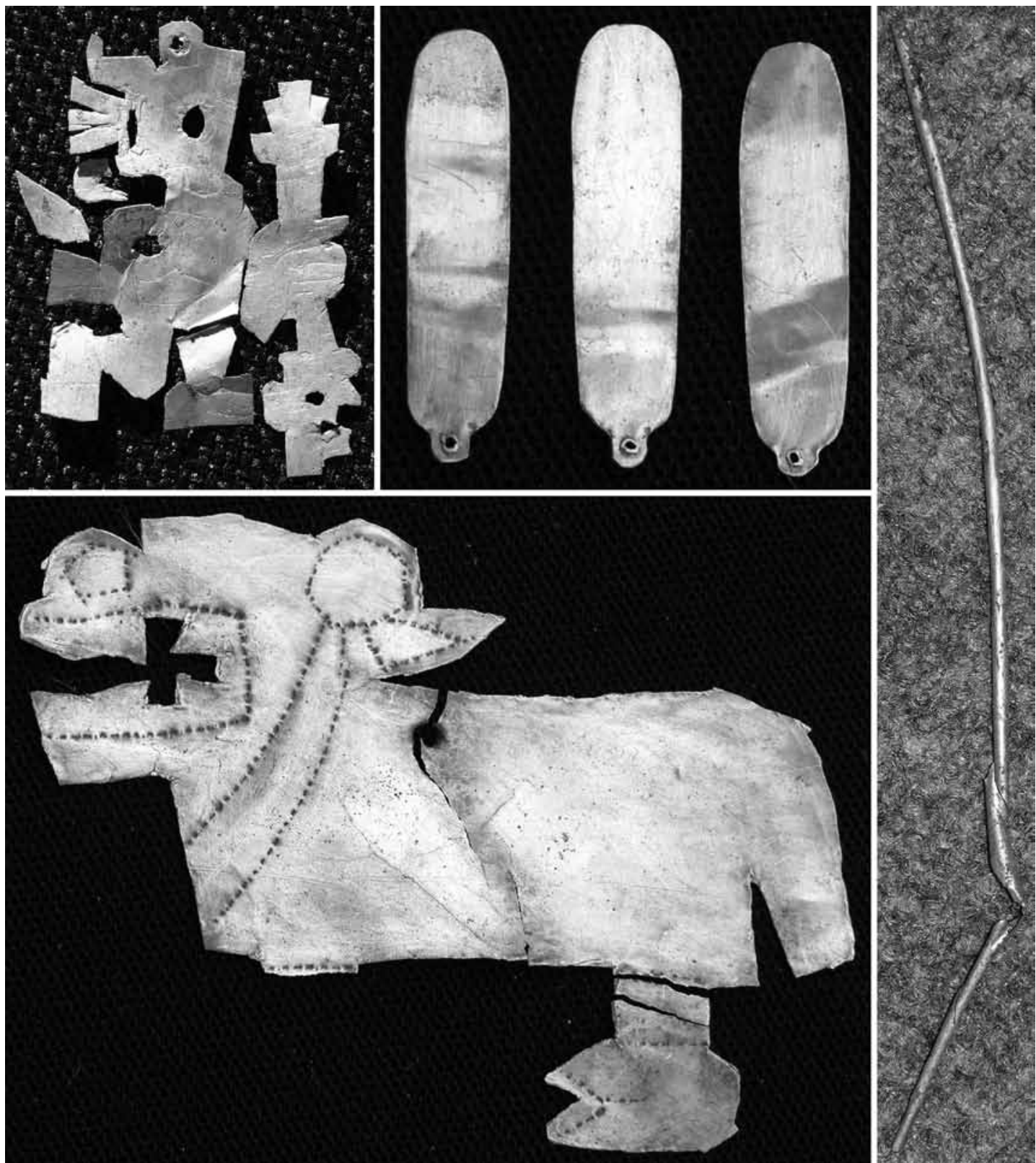

Figura 13. Pequeños objetos de oro del rasgo 2 de Pariti. Arriba, de izquierda a derecha: un "Personaje de Perfil" (altura 2,3 cm) y tres ornamentos alargados con perforación en un extremo (alturas ca. $2 \mathrm{~cm}$ ). Abajo, el llamado wari willka (altura 3,6 cm). Derecha, una paja o tubo de lámina de oro enrollada (longitud ca. $17 \mathrm{~cm}$ ). Los artefactos no aparecen a la misma escala (fotos A. Korpisaari). Small gold objects from feature 2 of Pariti. Above, from left to right: a "Individual in Profile" (height $2.3 \mathrm{~cm}$ ) and three elongated ornaments with a perforation at one end (heights ca. $2 \mathrm{~cm}$ ). Below, a so-called wari willka (height $3.6 \mathrm{~cm}$ ). Right, a straw or tube of rolled-up gold leaf (length ca. $17 \mathrm{~cm}$ ). The artifacts are not illustrated to scale (photos A. Korpisaari).

Estos incluyen kerus prosopomorfos, vasijas de servir de base anular (en el caso de la colección de Pariti, escudillas, botellones y algunas vasijas arriñonadas) y el motivo de volutas continuas en por lo menos 28 recipientes de los rasgos 1 y 2 de Pariti.
Nuestros hallazgos en Pariti refuerzan la opinión de que el "estilo corporativo" tiwanakota era bastante heterogéneo incluso en el área nuclear, difiriendo (ligeramente) entre subregiones y/o entre tipos de contexto (Alconini 1995; Burkholder 1997; Janusek 
2003; véase también Bennett 1936:455-456). Es posible que esta heterogeneidad estilística guarde correlaciones con el carácter multiétnico de la población del área nuclear tiwanakota (e.g., Browman 1994; Kolata 1993; Pärssinen 2005).

Aunque la cerámica de Pariti difiere del material del sitio-tipo Tiwanaku en los aspectos arriba mencionados, las formas, los engobes rojos y naranjas y los motivos iconográficos de la gran mayoría de las vasijas se parecen a los del Tiwanaku Clásico de Bennett / Tiwanaku IV de Ponce. Las dataciones radiocarbónicas bastante tardías de Pariti indican que cerámica tiwanakota de estilo y calidad "clásicos" se usaba en la región del Lago Titicaca por lo menos hasta aproximadamente el año 1.000 d.C. Esta observación apuntala la idea recientemente esbozada por varios investigadores (e.g., Alconini 1995; Burkholder 1997; Isbell y Knobloch 2009; Janusek 2003) de que los estilos Tiwanaku IV y V eran relativamente contemporáneos. Los fechados de Pariti son bastante tardíos también cuando se toma en cuenta que varios estudiosos argumentan que el Estado tiwanakota colapsaba ya hacia el año 1.000/1.050 d.C. (Augustyniak 2004; Isbell y Knobloch 2009; Owen 2005; cf. Ponce 1981). A la luz de estas aserciones, las dataciones radiocarbónicas apoyarían la interpretación de los rasgos 1 y 2 como una ofrenda terminal.

Otro asunto a considerar se refiere al grado de influencia cochabambina que parece estar presente en la colección de Pariti. Los estudiosos consideran al ch'allador como una forma de vasija originalmente desarrollada en la región de Cochabamba, de donde se habría difundido al área nuclear tiwanakota alrededor de 800 d.C. (Janusek 2003:62; véase también Anderson 2009). Además, la forma específica del ch'allador de Pariti es muy similar a la de los ch'alladores Mojocoya (véase Salinas 2007). Como ya hemos discutido, la colección de los rasgos de Pariti incluye 67 ch'alladores. Eso significa que el ch'allador es la segunda forma de vasija más común de la colección, precedido sólo por la escudilla $(n=82)$. Nunca antes se había encontrado ch'alladores en tales proporciones relativas en un sitio del área nuclear de Tiwanaku.

Aunque la pasta de los ch'alladores de Pariti es similar a la de los demás recipientes de la colección (Fernández 2006), y su decoración pintada no aparenta ser ni típicamente tiwanakota ni cochabambina, el papel central de vasijas de esta forma en los depósitos de ofrendas (y ceremonias) pariteñas nos hace pensar que el grupo (o grupos) que manufacturaba el material pariteño tenía algún tipo de contacto con el área de Cochabamba. Desafortunadamente, la interpretación del carácter de estos contactos es algo complicada, pues mientras algunos estudiosos argumentan que los tiwanakotas fundaron colonias y/o enclaves en Cochabamba (e.g., Janusek 2008; Kolata 1993), otros sugieren una dinámica de intercambio de bienes e influencias culturales entre ambas regiones (e.g., Browman 1997; Higueras 1996; Oakland 1986).

Hay también indicadores de que quienes manufacturaban y/o usaban la cerámica de Pariti poseían convenciones parecidas a las de la esfera cultural Wari. Los rasgos 1 y 2 en sí mismos, tienen como equivalentes más cercanos a los depósitos de cerámica ceremonial quebrada intencionalmente de los sitios Wari de Pacheco (e.g., Menzel 1964:23-28), Conchopata (e.g., Cook 1984-1985; Isbell 2001:3644; Isbell y Knobloch 2006), Ayapata (Ravines 1968, 1977) y Maymi (Anders 1990) ${ }^{4}$. La mayoría de las ofrendas Wari de este tipo incluía tiestos de algunos recipientes que llevaban representaciones pintadas del "Dios de los Báculos" y/o los "Personajes de Perfil", las que también decoran algunos kerus, escudillas y botellones de Pariti ${ }^{5}$. Además, los equivalentes más cercanos de los cuatro vasos pie pariteños provienen del área cultural Wari (véase Berrin 1997:178; Longhena y Alva 1999:51). Si suponemos una influencia cultural Wari, esta probablemente habría pasado al altiplano/Pariti a través de la colonia tiwanakota del valle medio de Moquegua, donde una franja fronteriza de solamente unos kilómetros de ancho separaba a los colonos de Tiwanaku y Wari (Goldstein 2005; Williams 2009). También, debido a similitudes estructurales entre las tumbas tiwanakotas de la porción menor del Titicaca y del valle medio de Moquegua, Korpisaari (2006:156) argumenta que una porción considerable de los colonizadores tiwanakotas de Moquegua provenía del área del lago. Si esto es correcto, es probable que los colonizadores mantuvieran contactos estrechos con los habitantes de dicha subregión del Titicaca.

Muchas cuestiones sobre el material arqueológico tremendamente rico -y sorprendentemente "cosmopolita"- de Pariti aún quedan sin responder, pero es probable que su presencia en la isla tenga que ver con el papel sacro y central del Lago Titicaca en la mitología centro-andina. Importantes sitios tiwanakotas se ubican en islas de la porción mayor del Titicaca (véase Bauer y Stanish 2001; Stanish y Bauer 2004). Por consiguiente, parece que 
los tiwanakotas -como después los incas- habían apropiado la sacralidad del Lago Titicaca para sus propios fines. Sin embargo, el presente trabajo ha descrito un contexto de ofrenda y un material votivo con características distintivas, fuertemente heterogéneas, que sugieren que la sacralidad de Pariti -y posiblemente de la porción menor del Titicaca- es cualitativamente distinta a la sacralidad de la porción mayor del lago. Nuestros hallazgos en Pariti refuerzan la idea de una relación evidente entre el Titicaca sacro y el Estado Tiwanaku, pero también permiten sugerir que las distintas porciones del Titicaca fueron escenario de prácticas ceremoniales diferenciadas.
Agradecimientos: Las investigaciones arqueológicas en la isla Pariti (temporadas 2004-2006) fueron auspiciadas por la Universidad de Helsinki y la Fundación Cultural de Finlandia. Durante partes del proceso de investigación, Korpisaari disfrutó de becas otorgadas por Dumbarton Oaks y la Fundación de Emil Aaltonen, y Villanueva de una beca MECESUP2. Queremos agradecer a Martti Pärssinen, supervisor del proyecto, $\mathrm{y}$ al equipo de trabajo de campo y laboratorio. Asimismo, al Comité Asesor Editorial y dos evaluadores de Chungara por sus comentarios, a la comunidad de Pariti por la acogida y ayuda, y a nuestras familias por el cariño y apoyo constante.

\section{Referencias Citadas}

Alconini, S. 1995. Rito, Símbolo e Historia en la Pirámide de Akapana, Tiwanaku: Un Análisis de Cerámica Ceremonial Prehispánica. Acción, La Paz.

Anders, M.B. 1990. Maymi: un sitio del Horizonte Medio en el valle de Pisco. Gaceta Arqueológica Andina V(17):27-39.

Anderson, K. 2009. Tiwanaku influence on local drinking patterns in Cochabamba, Bolivia. En Drink, Power, and Society in the Andes, editado por J. Jennings y B.J. Bowser, pp. 167-199. University Press of Florida, Gainesville.

Augustyniak, S. 2004. Dating the Tiwanaku state. Chungara Revista de Antropología Chilena 36:19-35.

Bauer, B.S. y C. Stanish 2001. Ritual and Pilgrimage in the Ancient Andes: The Islands of the Sun and the Moon. University of Texas Press, Austin.

Bennett, W.C. 1936. Excavations in Bolivia. Anthropological Papers of the American Museum of Natural History, Vol. XXXV, Part IV:329-507.

Berrin, K. (ed.) 1997. The Spirit of Ancient Peru: Treasures from the Museo Arqueológico Rafael Larco Herrera. Thames \& Hudson, Londres.

Browman, D.L. 1994. Titicaca basin archaeolinguistics: uru, pukina and aymara AD 750-1450. World Archaeology 26:235-251.

- - - 1997. Political institutional factors contributing to the integration of the Tiwanaku state. En Emergence and Change in Early Urban Societies, editado por L. Manzanilla, pp. 229-243. Plenum, Nueva York y Londres.

Burkholder, J.E. 1997. Tiwanaku and the Anatomy of Time: A New Ceramic Chronology from the Iwawi Site, Department of La Paz, Bolivia. Doctoral Dissertation, State University of New York, Binghamton. University Microfilms, Ann Arbor.

Callisaya, L. 2005. Análisis de los huesos de mamíferos y aves de Pariti. Manuscrito en posesión de los autores.

- - - 2006. Análisis de los huesos de mamíferos y aves de Pariti (temporada 2005). Manuscrito en posesión de los autores.
Cobo, B. 1990 [1653]. Inca Religion and Customs. University of Texas Press, Austin.

Cook, A.G. 1984-1985. The Middle Horizon ceramic offerings from Conchopata. Nawpa Pacha 22-23:49-90.

Fernández, M.S. 2006. Informe preliminar de análisis cerámico de vasijas de servir. Manuscrito en posesión de los autores.

Goldstein, P.S. 2005. Andean Diaspora: The Tiwanaku Colonies and the Origins of South American Empire. University Press of Florida, Gainesville.

Higueras-Hare, A. 1996. Prehispanic Settlement and Land Use in Cochabamba, Bolivia. Doctoral Dissertation, University of Pittsburgh, Pittsburgh. University Microfilms, Ann Arbor.

Isbell, W.H. 2001. Repensando el Horizonte Medio: el caso de Conchopata, Ayacucho, Perú. Boletín de Arqueología PUCP 4:9-68.

Isbell, W.H. y P.J. Knobloch 2006. Missing links, imaginary links: Staff God imagery in the South Andean past. En Andean Archaeology III: North and South, editado por W.H. Isbell y H. Silverman, pp. 307-351. Springer, Nueva York.

- - 2009. SAIS-the origin, development, and dating of Tiahuanaco-Huari iconography. En Tiwanaku: Papers from the 2005 Mayer Center Symposium at the Denver Art Museum, editado por M. Young-Sánchez, pp. 165-210. Denver Art Museum, Denver.

Janusek, J.W. 2003. Vessels, time, and society: toward a ceramic chronology in the Tiwanaku heartland. En Tiwanaku and Its Hinterland 2: Urban and Rural Archaeology, editado por A.L. Kolata, pp. 30-91. Smithsonian Institution Press, Washington D.C.

- - - 2004. Identity and Power in the Ancient Andes: Tiwanaku Cities through Time. Routledge, Nueva York.

- - - 2008. Ancient Tiwanaku. Cambridge University Press, Cambridge y Nueva York.

Kolata, A.L. 1993. The Tiwanaku: Portrait of an Ancient Civilization. Blackwell, Cambridge y Oxford. 
- - - 2003. Tiwanaku ceremonial architecture and urban organization. En Tiwanaku and Its Hinterland 2: Urban and Rural Archaeology, editado por A.L. Kolata, pp. 175-201. Smithsonian Institution Press, Washington D.C.

Korpisaari, A. 2006. Death in the Bolivian High Plateau: Burials and Tiwanaku Society. BAR International Series 1536, Oxford.

Korpisaari, A. y M. Pärssinen (eds.) 2005. Pariti: Isla, Misterio y Poder. El Tesoro Cerámico de la Cultura Tiwanaku. República de Bolivia y República de Finlandia, La Paz.

- - - 2011. Pariti: The Ceremonial Tiwanaku Pottery of an Island in Lake Titicaca. Academia Scientiarum Fennica, Helsinki.

Korpisaari, A., I.E. Sääksjärvi y M. Salo 2009. Evidencias de contactos entre la sierra, la ceja de selva y la selva baja en el arte de la cultura Tiwanaku. En Actas del Taller Andes, Amazonas y sus Transformaciones, editado por T. Platt, I. Daillant, M. Harris y G. Rivière, en prensa.

Korpisaari, A. y J. Sagárnaga 2007. Investigaciones arqueológicas en la isla Pariti, Bolivia: temporadas de campo 2004, 2005 y 2006. Chachapuma 1:7-30.

- - - 2009. Investigaciones arqueológicas en la isla Pariti, Bolivia: temporada de campo 2004. Boletín del Centro de Estudios Precolombinos de la Universidad de Varsovia 7:387-410.

Korpisaari, A., J. Sagárnaga y R. Väisänen 2011. Archaeological excavations on the island of Pariti, Bolivia: new light on the Tiwanaku period in the Lake Titikaka region. Ancient America 11:1-51.

Longhena, M. y W. Alva 1999. Splendours of the Ancient Andes. Thames \& Hudson, Londres.

Lothrop, S.K. 1956. Peruvian pacchas and keros. American Antiquity 21:233-243.

Manzanilla, L. 1992. Akapana: Una Pirámide en el Centro del Mundo. Universidad Nacional Autónoma de México, Instituto de Investigaciones Antropológicas, México D. F.

McCormac, F.G., A.G. Hogg, P.G. Blackwell, C.E. Buck, T.F.G. Higham y P.J. Reimer 2004. SHCal04 southern hemisphere calibration, 0-11.0 cal kyr BP. Radiocarbon 46:1087-1092.

Menzel, D. 1964. Style and time in the Middle Horizon. Nawpa Pacha 2:1-105.

Oakland, A.S. 1986. Tiwanaku Textile Style from the South Central Andes, Bolivia and North Chile. Doctoral Dissertation, University of Texas, Austin. University Microfilms, Ann Arbor.

Owen, B.D. 2005. Distant colonies and explosive collapse: the two stages of the Tiwanaku diaspora in the Osmore drainage. Latin American Antiquity 16:45-80.

Pärssinen, M. 2005. Tiwanaku: una cultura y un estado andinos. En Pariti: Isla, Misterio y Poder. El Tesoro Cerámico de la Cultura Tiwanaku, editado por A. Korpisaari y M. Pärssinen, pp. 17-37. República de Bolivia y República de Finlandia, La Paz.
Patiño, T. y J. Villanueva 2006. Excavación y análisis del material arqueológico del pozo 7, isla Pariti. Ponencia presentada en I Reunión Anual SALP, La Paz.

- - - 2009. El conjunto cerámico "corporativo" de Tiwanaku en la ofrenda de Pariti. En Anales de la XXII Reunión Anual de Etnología Tomo I, pp. 75-84. MUSEF, La Paz.

Ponce, C. 1981. Tiwanaku: Espacio, Tiempo y Cultura. Ensayo de Síntesis Arqueológica. Los Amigos del Libro, La Paz y Cochabamba.

Ponce, C., J. Reinhard, M. Portugal, E. Pareja y L. Ticlla 1992. Exploraciones Arqueológicas Subacuáticas en el Lago Titikaka. La Palabra, La Paz.

Posnansky, A. 1957. Tihuanacu: La Cuna del Hombre Americano, Vols. III-IV. Ministerio de Educación, La Paz.

Ramos Gavilán, A. 1988 [1621]. Historia del Santuario de Nuestra Señora de Copacabana. Lima.

Ravines, R. 1968. Un depósito de ofrendas del Horizonte Medio en la sierra central del Perú. Ñawpa Pacha 6:19-45.

- - - 1977. Excavaciones en Ayapata, Huancavelica, Perú. Ñawpa Pacha 15:49-100.

Sagárnaga, J. 2007. Máscaras y culto en Tiwanaku. Chachapuma $1: 31-51$

- - - 2009. Alianza y ritualidad en Tiwanaku: las vasijas pares de Pariti. Chachapuma 4:5-25.

Sagárnaga, J. y A. Korpisaari 2009. Investigaciones arqueológicas en la isla Pariti, Bolivia: temporada de campo 2005. Boletín del Centro de Estudios Precolombinos de la Universidad de Varsovia 7:411-429.

Salinas, E. 2007. Cerámica Mojocoya: Formas y Decoración. UMRPSFXCH y Proyecto Sucre Ciudad Universitaria, Sucre.

Stanish, C. y B.S. Bauer (eds.) 2004. Archaeological Research on the Islands of the Sun and Moon, Lake Titicaca, Bolivia: Final Results from the Proyecto Tiksi Kjarka. Monograph 52, Cotsen Institute of Archaeology, University of California, Los Angeles.

Väisänen, R. 2008. Pacha Mama's Treasures: A Study of the Morphological Types of Ceremonial Tiwanaku Ceramics Found on the Island of Pariti, Lake Titicaca, Bolivia. Tesis para optar al grado de Magister en Filosofía, Departamento de Arqueología, Universidad de Helsinki, Helsinki.

Varela, V. 2002. Enseñanzas de alfareros toconceños: tradición y tecnología en la cerámica. Chungara Revista de Antropología Chilena 34:225-252.

Villanueva, J. 2007. Las escudillas del rasgo 1 en la isla de Pariti: interpretación y consideraciones desde un enfoque iconográfico. Chachapuma 1:53-63.

Williams, P.R. 2009. Wari and Tiwanaku borderlands. En Tiwanaku: Papers from the 2005 Mayer Center Symposium at the Denver Art Museum, editado por M. Young-Sánchez, pp. 211-224. Denver Art Museum, Denver. 


\section{Notas}

1 El término torus refiere a un anillo ligeramente saliente presente en muchos kerus tiwanakotas en su exterior (véase Janusek 2003:61-62).

2 Las vasijas de uno de los dos pares tienen rostros de varón que se desprenden de cuerpos en forma de una fruta con una base de cuatro protuberancias semiesféricas, es decir, estos varones modelados son más abstractos que las demás piezas de esta categoría.

3 Sin embargo, al terminar el período de reconstrucción de las vasijas ofrendadas, sobraban docenas de tiestos de tinajas grandes; por lo tanto, el número original de estas vasijas de almacenamiento probablemente era algo más de siete.
$4 \quad$ En la esfera de influencia Tiwanaku, el equivalente más cercano para los rasgos 1 y 2 de Pariti es el llamado "Akapana Kero Smash" (véase Manzanilla 1992; también Kolata 1993:123-124, 2003:191). No obstante, este último difiere de las ofrendas de Pariti en que no se habían enterrado los fragmentos de los recipientes quebrados en un bolsón (o varios), sino se los había dispersado sobre una terraza del templo de Akapana. Asimismo el bolsón de La Karaña (Tiwanaku) hallado casualmente por guarda-ruinas y reportado por Oswaldo Rivera.

5 Tres vasijas de los rasgos 1 y 2 de Pariti llevan la imagen del "Dios de los Báculos" y 17 la de los "Personajes de Perfil” (véase Korpisaari y Pärssinen 2011). 
